\title{
Mineralogy and geochemistry of the Tonmittelsalz (z3TM) and Tonbrockensalz (z4TS) as "zuber" equivalents in the German Zechstein (Upper Permian)
}

\author{
Julia ONNEKEN ${ }^{1}$, Michael SCHRAMM ${ }^{1, *}$ and Jörg HAMMER ${ }^{1}$ \\ 1 Federal Institute for Geosciences and Natural Resources (BGR), Stilleweg 2, 30655 Hannover, Germany
}

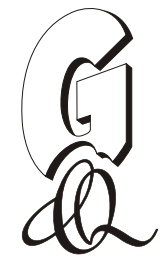

Onneken, J., Schramm, M., Hammer, J., 2018. Mineralogy and geochemistry of the Tonmittelsalz (z3TM) and Tonbrockensalz (z4TS) as "zuber" equivalents in the German Zechstein (Upper Permian). Geological Quarterly, 62 (4): 896-916, doi: 10.7306/gq.1446

Associate editor: Wojciech Granoszewski

Two main lithostratigraphic units of clay-bearing rock salt, the Tonmittelsalz of the Leine formation (z3) and Tonbrockensalz of the Aller formation (z4), occur in the German Zechstein (Upper Permian) succession. These units could be equivalents of the Brown Zuber (Na3t) and Red Zuber (Na4t) in the PZ3 and PZ4 cyclothemes of the Polish Zechstein basin. Mineralogical-geochemical investigations of the Tonmittelsalz and Tonbrockensalz were carried out on samples taken from a deep borehole in the Gorleben salt dome in Northern Germany. Even though these units are characterized by a similar mineralogical composition of mainly halite with subordinate quantities of anhydrite and clay minerals, variations in mineral content and fabric were observed. The older Tonmittelsalz rocks document some primary features like chevrons in halite crystals and idiomorphic halite crystals in clay-bearing layers. A brecciated fabric and a vague layering, shown by polarizing microscopy and CT-imaging, indicate a deformation of the younger Tonbrockensalz, which is folded in the deep borehole Go1004. Nevertheless, internal fabrics of clay clasts in the z4TS show an early brecciated and folded fabric during sedimentation or diagenesis. Main component chemistry and REE are comparable in both units, but significant differences were observed for trace element and isotope data. The Z3TM rocks contain higher values of trace elements like Li and higher values in REE, while the z4TS rocks are enriched in K. Isotope data of anhydrites of both units correspond to those of the Zechstein. The $\delta^{18} \mathrm{O}$ values of samples from the Tonbrockensalz display a relatively large range $(8.5-11.9 \%$ ) and may indicate changing conditions during its formation. In contrast, only minor variations in the $\delta^{34} \mathrm{~S}$ of samples from the Tonbrockensalz and in both isotope compositions of samples from the Tonmittelsalz have been documented.

Key words: clay-bearing strata, Tonmittelsalz, Tonbrockensalz, Zechstein, zuber, North Germany.

\section{INTRODUCTION}

One of the most interesting lithologies in the evaporites of the Zechstein basin (Upper Permian) are clay-bearing salt strata, e.g. the clay-bearing rock salt layers occurring in the upper part of the Leine ( $\mathrm{z} 3$ ) and Aller ( $\mathrm{z} 4)$ cyclothem successions (called here "formations") of the North German Zechstein Basin (NGZB; Fig. 1). During the sedimentation of saline formations, there were frequent periods of terrigenous clastic deposition of salt-clays and clay-bearing salt layers. In this paper, clay is understood as clay minerals and does not refer to the grain size. Different lithological types of clay-bearing rock salt developed locally depending on the palaeogeography of the Zechstein basin and the prevailing sedimentary conditions. So-called salt-clay units like the Grauer Salzton (Z3GT) and Roter Salzton ( $\mathrm{Z} 4 \mathrm{RT}$ ) of the German Zechstein succession are found at the bases of evaporitic cycles, while clay-bearing rock salt, called

\footnotetext{
* Corresponding author, e-mail: michael.schramm@bgr.de
}

Received: April 5, 2018; accepted: September 10, 2018; first published online: December 28, 2018 "zuber" in the Polish Zechstein basin, occurs in the overlying strata, reflecting cessation of evaporite deposition by increased terrigenous input (Table 1; e.g., Wagner, 1994; Wagner and Peryt, 1997).

To obtain a better understanding of the relevance of clay minerals (in clay strata or clay-bearing strata) with regard to sedimentation, diagenesis and salt diapirism as well as to evaluate their significance in relation to safety aspects in potential radioactive waste disposal, the Federal Institute for Geosciences and Natural Resources (BGR) started mineralogical, geochemical and stable isotope studies of different Zechstein clay-bearing salt units (Table 1). At the top of the Leine Formation, the clay-bearing salt strata of the Tonmittelsalz (z3TM) are located (e.g., Herde, 1953; Bornemann et al., 2008). Tonbrockensalz (z4TS, Bornemann et al., 2008) and Tonbanksalz (z4TB), which is an equivalent of the Tonbrockensalz found only in the Asse salt dome (Klarr and Paul, 1991), are located in the upper part of the Aller Formation. Based on borehole logs, the Zechstein z3 to $z 7$ evaporites of the German Zechstein Basin can potentially be correlated with the salt-clay Zechstein strata of the Polish Zechstein Basin. Käding (2000) linked the Tonmittelsalz and Roter Salzton to the Gwda Formation including the Brown Zuber (Na3t) in the PZ3 cyclothem (Wachowiak et al., 2014) as well as the Tonbrocken- 


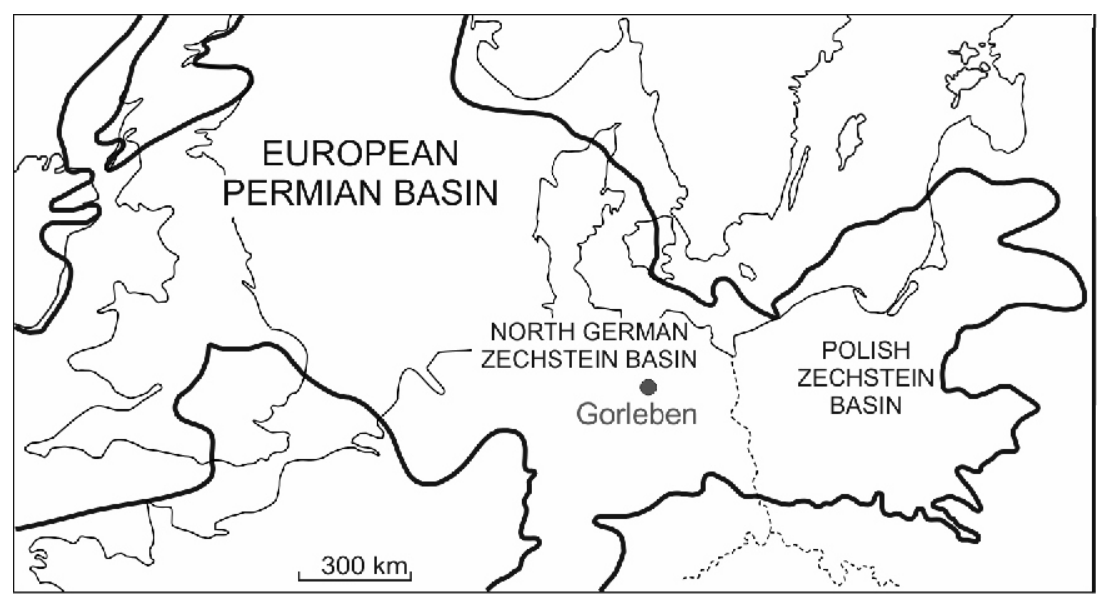

Fig. 1. Late Permian palaeogeography of the European Permian Basin (basinal extent of the Zechstein 2 cycle after Słowakiewicz and Mikołajewski, 2011; Czapowski and Tomassi-Morawiec, 2013) showing the location of the Gorleben salt dome, the North German Zechstein Basin (NGZB) and the Polish Zechstein Basin (PZB)

Correlation of Upper Zechstein lithostratigraphic units of the German and Polish Zechstein basins

\begin{tabular}{|c|c|c|c|c|c|}
\hline \multicolumn{6}{|c|}{ UPPER ZECHSTEIN (UPPER PERMIAN) LITHOSTRATIGRAPHIC UNITS } \\
\hline \multicolumn{2}{|c|}{ NORTH GERMAN ZECHSTEIN BASIN } & \multicolumn{4}{|c|}{ POLISH ZECHSTEIN BASIN } \\
\hline \multicolumn{2}{|c|}{ (after: Bornemann et al., 2008) } & \multicolumn{4}{|c|}{ (after: Wagner, 1991, 1994; Wagner and Peryt, 1997) } \\
\hline $\begin{array}{c}\text { Litostratigraphic } \\
\text { units }\end{array}$ & $\begin{array}{l}\text { Formation/ } \\
\text { Cyclotheme }\end{array}$ & $\begin{array}{c}\text { Evaporite + clastic } \\
\text { units }\end{array}$ & "Zuber" units & Subcyclotheme & Cyclotheme \\
\hline \multicolumn{6}{|c|}{ Mölln Formation (z7) } \\
\hline \multicolumn{6}{|c|}{ Friesland Formation(z6) } \\
\hline \multirow{3}{*}{\multicolumn{2}{|c|}{ Ohre Formation (z5) }} & $\begin{array}{l}\text { Top Youngest } \\
\text { Halite (Na4b2) }\end{array}$ & Ina Formation & \multirow{4}{*}{ Pz4b } & \multirow{11}{*}{$\mathrm{P} z 4$} \\
\hline & & $\begin{array}{l}\text { Upper Red Pelite - } \\
\text { upper part (T4b2) }\end{array}$ & \multirow{4}{*}{$\begin{array}{l}\text { Korytnica } \\
\text { Formation }\end{array}$} & & \\
\hline & & \begin{tabular}{|c|} 
Intrastratal Halite \\
$($ Na4b1)
\end{tabular} & & & \\
\hline $\begin{array}{l}\text { Oberer Aller-Ton } \\
\text { (z4OT) }\end{array}$ & \multirow{8}{*}{$\begin{array}{l}\text { Aller Formation } \\
\qquad(\mathrm{z} 4)\end{array}$} & $\begin{array}{l}\text { Upper Red Pelite - } \\
\text { lower part (T4b1) }\end{array}$ & & & \\
\hline $\begin{array}{c}\text { *Tonbrockensalz } \\
(\mathrm{z} 4 \mathrm{TS})= \\
\text { Tonbanksalz (z4TB) }\end{array}$ & & $\begin{array}{c}\text { Upper Youngest } \\
\text { Clay Halite (Na4t) } \\
\text { "Red Zuber" }\end{array}$ & & \multirow{7}{*}{ Pz4a } & \\
\hline \multirow{3}{*}{$\begin{array}{l}\text { Aller Steinsalz } \\
\text { (z4BS-z4RS) }\end{array}$} & & $\begin{array}{c}\text { Upper Youngest } \\
\text { Halite (Na4a2) }\end{array}$ & & & \\
\hline & & $\begin{array}{l}\text { Upper Pegmatite } \\
\text { Anhydrite (A4a2) }\end{array}$ & & & \\
\hline & & $\begin{array}{c}\text { Lower Youngest } \\
\text { Halite (Na4a1) }\end{array}$ & $\begin{array}{l}\text { Parsęta } \\
\text { Formation }\end{array}$ & & \\
\hline \multirow{2}{*}{$\begin{array}{l}\text { Pegmatitanhydrit } \\
\text { (z4PA) }\end{array}$} & & $\begin{array}{l}\text { Lower Pegmatite } \\
\text { Anhydrite (A4a1) }\end{array}$ & & & \\
\hline & & $\begin{array}{c}\text { Underlying Halite } \\
(\mathrm{Na} 4 \mathrm{a} 0)\end{array}$ & & & \\
\hline Roter Salzton (z4RT) & & $\begin{array}{c}\text { Lower Red Pelite } \\
\text { (T4a) }\end{array}$ & \multirow{2}{*}{$\begin{array}{l}\text { Gwda } \\
\text { Formation }\end{array}$} & & \\
\hline $\begin{array}{c}\text { *Tonmittelsalz } \\
(\mathrm{z} 3 \mathrm{TM})\end{array}$ & \multirow{5}{*}{$\begin{array}{l}\text { Leine Formation } \\
\qquad(\mathrm{z} 3)\end{array}$} & $\begin{array}{l}\text { Younger Clay } \\
\text { Halite (Na3t) } \\
\text { "Brown Zuber" }\end{array}$ & & \multirow{5}{*}{\multicolumn{2}{|c|}{$\mathrm{Pz} 3$}} \\
\hline $\begin{array}{c}\text { Leine Steinsalz + } \\
\text { Kalisalze } \\
(\mathrm{z} 3 \mathrm{BS}-\mathrm{z3RI})\end{array}$ & & $\begin{array}{c}\text { Younger Halite } \\
\text { (Na3) + Younger } \\
\text { Potash (K3) }\end{array}$ & \multirow{4}{*}{$\begin{array}{l}\text { Lack of "zuber" } \\
\text { deposits }\end{array}$} & & \\
\hline $\begin{array}{c}\text { Hauptanhydrit } \\
(\mathrm{z} 3 \mathrm{HA})\end{array}$ & & $\begin{array}{l}\text { Main Anhydrite } \\
\text { (A3) }\end{array}$ & & & \\
\hline $\begin{array}{c}\text { Leine-Karbonat } \\
\text { (z3LK) }\end{array}$ & & $\begin{array}{l}\text { Platy Dolomite } \\
\text { (Ca3) }\end{array}$ & & & \\
\hline $\begin{array}{c}\text { Grauer Salzton } \\
\text { (z3GT) }\end{array}$ & & Grey Pelite (T3) & & & \\
\hline
\end{tabular}

*studied clay-bearing strata 


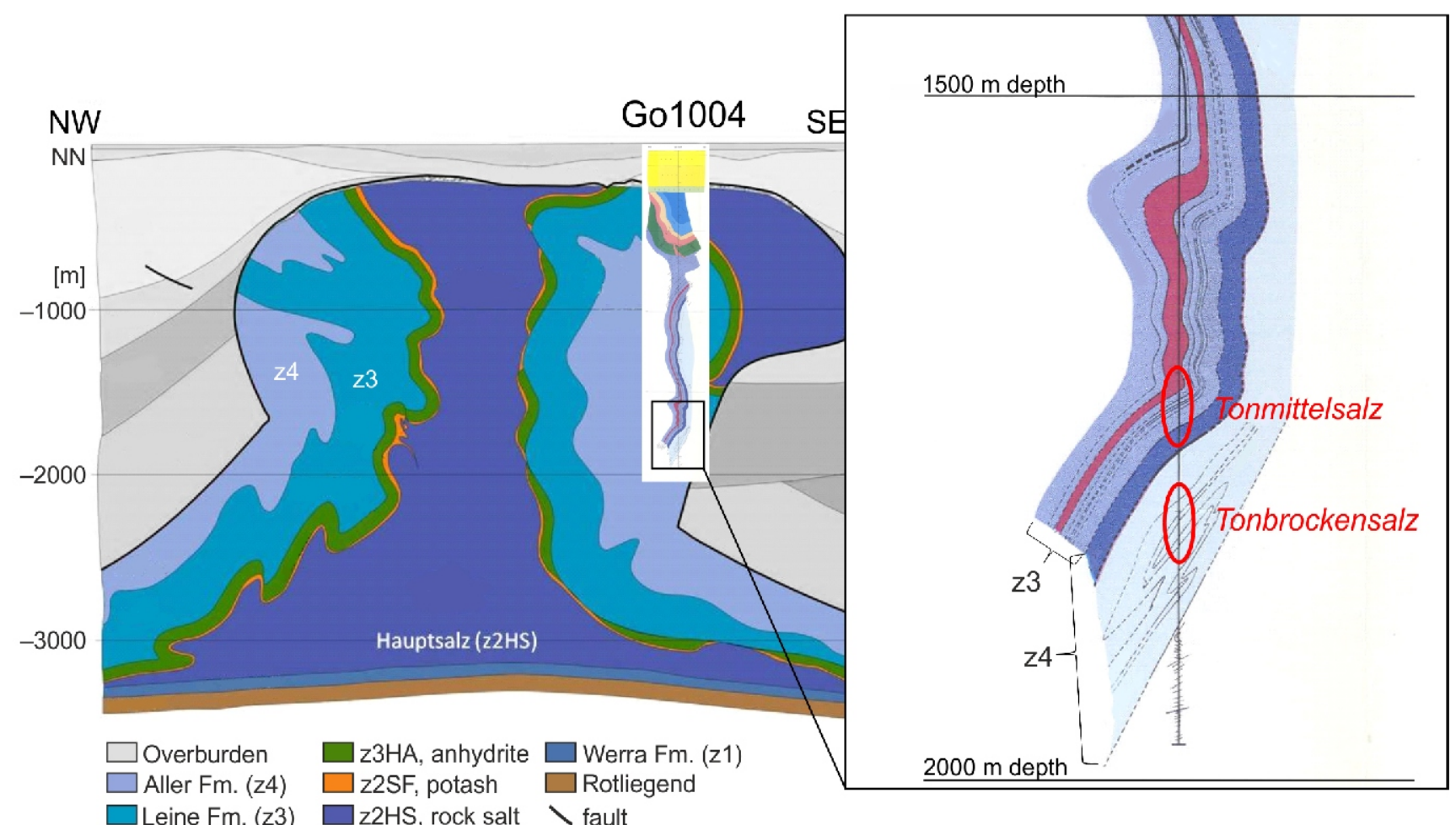

Fig. 2. NW-SE oriented cross-section through the Gorleben salt dome with position and profile of borehole Go1004

To the right, enlarged profile showing sampling intervals (modified after Bornemann, 1991; Bornemann et al., 2008)

salz and Tonbanksalz to the Korytnica Formation of the PZ4 cyclothem (Wagner, 1991, 1994; Natkaniec-Nowak et al., 2014). The Red Zuber (Na4t) unit, distinguished in salt domes of central Poland, is located at the top of the PZ4 in the axial part of the Polish Zechstein Basin and is considered to be equivalent to the Korytnica, Ina and Piława formations, corresponding to the Ohre to Mölln formations in the NGZB (Wagner, 1991, 1994).

\section{MATERIAL AND METHODS}

The investigations are focused on two clay-bearing rock salt units: the Tonmittelsalz (Z3TM) and the Tonbrockensalz (z4TS). The samples were taken from the deep borehole Go1004, located on the southeastern flank of the Gorleben salt dome (Fig. 2). The layers in the salt dome flank are steeply oriented and folded (Bornemann and Fischbeck, 1988). The Gorleben salt dome is located in the eastern part of Lower Saxony. The salt table is $\sim 250 \mathrm{~m}$ below ground level whilst the base of the Zechstein lies at a depth between 3200 and $3400 \mathrm{~m}$ below ground level (Bornemann et al., 2008).

To analyse the mineral phases and microstructures of the rocks, polarizing microscopy, scanning electron microscopy (SEM) and computer tomography (CT) have been used. Moreover, mineralogical and geochemical investigations have been performed. Two aliquots for the $\mathrm{H}_{2} \mathrm{O}$-soluble fraction and one aliquot for the $\mathrm{H}_{2} \mathrm{O}$-insoluble fraction as well as bulk samples have been investigated (Fig. 3).

$\mathrm{H}_{2} \mathrm{O}$-soluble fractions. An aliquot was dissolved with double-distilled water on a sample shaker for several days. From this digestion solution, geochemical analyses were carried out by Inductively Coupled Plasma Optical Emission Spectroscopy (ICP-OES; Spectro CIRUS ICP-OESR) for the major and minor components $\mathrm{Na}, \mathrm{K}, \mathrm{Mg}, \mathrm{Ca}, \mathrm{Cl}, \mathrm{SO}_{4}$ and the trace component bromide (for analytical details and limits of detection see Mertineit et al., 2014).

Based on the ICP-OES data, the quantitative mineral composition was calculated within a limited range. Due to the potentially significant $\mathrm{H}_{2} \mathrm{O}$-content of the salt clays, by contrast with typical rock salt, for which the mineral calculation program ZECHMIN-7® was mainly created (Bornemann et al., 2008), and to avoid miscalculations, the processing was restricted to the halite and anhydrite content.

In preparation of the sulphur and oxygen isotope ratio measurement of the sulphates, a further aliquot was dissolved with $10 \% \mathrm{NaCl}$ solution. The $\mathrm{pH}$ of the solution was controlled by $\mathrm{HCl}$ at $<2$ and heated to just below the boiling point. Under addition of $8.5 \% \mathrm{BaCl}_{2}$ solution, the dissolved sulphate (of anhydrite) precipitated as $\mathrm{BaSO}_{4}$. This material was used for the sulphur and oxygen isotope analyses. The sulphur isotope ratios of the sulphates were analysed with a ThermoFinnigan Delta Plus mass spectrometer $\AA$, connected to an elemental analyser (EA-IRMS) in a continuous flow treatment analogous to Montinaro et al. (2015). The isotope ratios are expressed as delta values $\left(\delta^{18} \mathrm{O}_{\mathrm{SO}}\right)$ relative to the Vienna Canyon Diabolo Troilite (VCDT) analogous to Hulston and Thode (1965). The oxygen isotope measurements were also performed in a continuous flow treatment using TC/EA-IRMS (thermal combustion-isotope ratio mass spectrometry) and a ThermoQuest Delta Plus XL- mass spectrometer (e.g., Montinaro et al., 2015). The measured oxygen isotope values are expressed as delta values $\left(\delta^{18} \mathrm{O}_{\mathrm{SO} 4}\right)$ relative to the Vienna Standard Mean Ocean Water (VSMOW) analogous to Seal et al. (2000). 


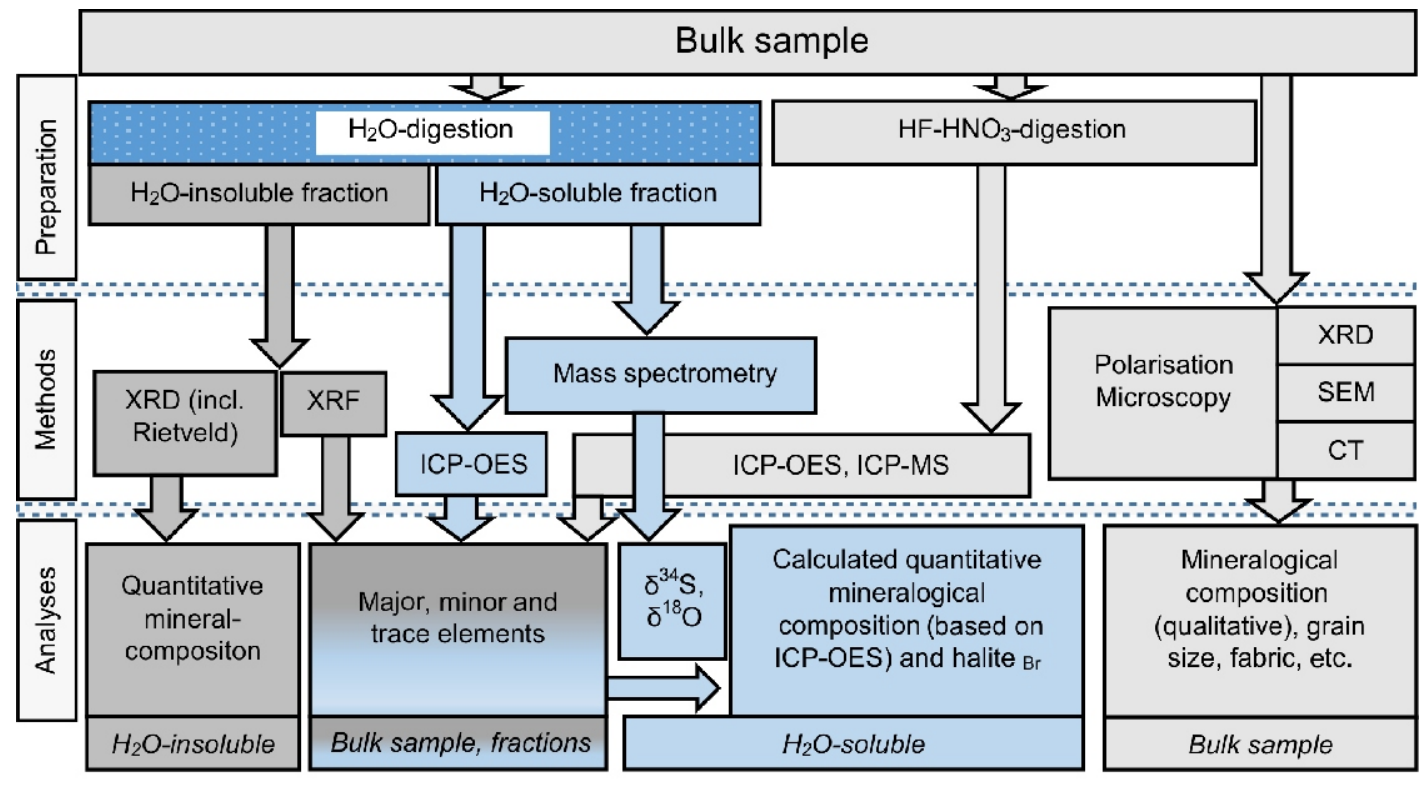

Fig. 3. Flow chart of the geochemical and mineralogical analyses

$\mathrm{H}_{2} \mathrm{O}$-insoluble fractions. Another aliquot was dissolved with double-distilled water on a sample shaker for several days and filtrated in vacuum equipment using Sartorius ${ }^{\circledR}$ membrane filters ( $<0.1 \mu \mathrm{m}$ mash size) in order to obtain the $\mathrm{H}_{2} \mathrm{O}$-insoluble residue. The $\mathrm{H}_{2} \mathrm{O}$-insoluble residue was analysed by X-ray fluorescence (XRF, PANalytical Axios $®$ ) in order to detect the main components, especially $\mathrm{Al}, \mathrm{K}, \mathrm{Mg}$ and $\mathrm{Si}$, as well as trace components. The detection limits of the components are: $0.05 \mathrm{wt} \%$, $\left(\mathrm{Al}_{2} \mathrm{O}_{3}\right), 0.005$ wt. $\%\left(\mathrm{~K}_{2} \mathrm{O}\right), 0.01$ wt. $\%(\mathrm{MgO})$ and 0.10 wt. $\%$ $\left(\mathrm{SiO}_{2}\right)$. X-ray diffraction (XRD; PANalytical MPD Pro®) combined with the Rietveld-method (Rietveld, 1969) was performed to determine the quantitative mineralogical composition.

Bulk sample. The mineral content was controlled by microscopy and partly by XRD. In addition to microscopy, XRD and SEM, geochemical analyses of the bulk rock samples were performed. An aliquot was dissolved with acid $\left(\mathrm{HF}-\mathrm{HNO}_{3}\right)$ for detecting the major, minor and trace elements by means of ICP-OES (Agilent Technologies 5100) and ICP-MS (iCAP Q Thermo Fisher), especially focused on the detection of the Al-, $\mathrm{K}-, \mathrm{Mg}$ - as well as the $\mathrm{Li}-, \mathrm{Rb}$ - and REE-content. The detection limits for ICP-OES in the solution is about $1 \mathrm{ppb}$ for all components analysed. For the ICP-MS, the detection limits in the solution e.g. for $\mathrm{Li}, \mathrm{Al}$ and $\mathrm{Rb}$ are: $0.146 \mathrm{ppt}, 82.6$ and $0.381 \mathrm{ppt}$, respectively.

Non-destructive computed tomography (CT; Phoenix $v \mid$ tome $\mid x m \AA$ ) combined with the CT data software VGStudio $M A X 3 . O B$ (volume graphics) has been used to investigate the internal structures, spatial distribution/quantification of phases and fabrics (e.g., Ketcham and Carlson, 2001; Thiemeyer et al., 2015) of the two rock types. The 3D visualization of rock fabrics, spatial distribution of minerals and fluid phases or fractures as well as porosity patterns allows a comprehensive characterization of rock fabrics in great detail (voxel size of $71.3 \mu \mathrm{m}$ ).

\section{RESULTS}

\section{PETROGRAPHIC STUDIES OF TONMITTELSALZ}

The Tonmittelsalz (z3TM) was encountered four times in the Go1004. This unit is divided into five subunits (Fig. 4) consisting of clay-bearing rock salt (z3TM1/t, z3TM2/t and z3TM3/t) with intercalated halitic rock salt (z3TM1/na and
z3TM2/na). The overall normal thickness is about $36 \mathrm{~m}$ (Bornemann et al., 2008). The microscopically studied section is located at a depth between 1713.5-1755.8 $\mathrm{m}$ and is overturned. The uppermost eight metres of the cored section up to $1742 \mathrm{~m}$ of $\mathrm{z} 3 \mathrm{TM} 3 / \mathrm{t}$ were destroyed during drilling and were not sampled.

The clay-bearing subunits of the z3TM unit (z3TM1/t, z3TM2/t, z3TM3/t) are made of grey-green and slightly orange rock salt with grey or red-brown clay-bearing flakes and layers (Fig. 5A). The amount of detritus increases towards the top of the Z3TM. The clay-bearing matrix appears between halite crystals as well as in layers: 1 to $3 \mathrm{~mm}$ thick in z3TM1/t and up to $5 \mathrm{~cm}$ thick in z3TM2/t and z3TM3/t. Halite crystals are fine to medium-grained ( 2 to $10 \mathrm{~mm}$ in diameter) with curved grain boundaries, triple junctions with angles approaching $120^{\circ}$ and with impurities sitting mainly along grain boundaries (Fig. 6B). Abundant fluid inclusions are concentrated along grain boundaries and within halite crystals. Some fluid inclusion trails are rectangular and look like chevron crystals (Fig. 6C). Joints with fibrous halite are occasionally associated with clay flakes (Fig. 6B). Idiomorphic quartz and magnesite crystals are common in the halite crystals (Fig. 6D). The clay-bearing matrix consists mainly of clay minerals, quartz, halite, anhydrite, chlorite, muscovite, magnesite and hematite (Fig. 5D). The grain size of these components varies between 50 and $150 \mu \mathrm{m}$ and most of the phyllosilicates are crypto-crystalline. A unique feature of the z3TM1/t subunit is anhydrite aggregates with rounded, lobate shapes up to $1.5 \mathrm{~mm}$ in size (Fig. 6A). Idiomorphic halite crystals of sizes up to $2 \mathrm{~cm}$ are often present in clay-bearing layers in z3TM2/t and especially in the top z3TM3/t subunit (Figs. 4 and $5 A-C$ ). Carnallite crystals were observed within the halitic matrix in all subunits (Fig. 8D). In the SEM, idiomorphic magnesite crystals were detected (Fig. 7B). Carnallite flakes on the surface of the thick sections probably grew out of prior fluid-filled pores after preparation (Fig. 7B). The CT analysis shows a more or less uniform distribution of clay and anhydrite without a preferred orientation (Fig. 9). Within the halite matrix, lobate pores with a fluid phase are associated with carnallite. CT imaging showed that the sample consists of 86.8 vol. $\%$ of halite, 12.8 vol. $\%$ of detrital phases and anhydrite as well as 0.4 vol. $\%$ of pore space at a resolution of $71.3 \mu \mathrm{m}$ voxel size (Fig. 4). Within these pores, 71.8 vol.\% comprised carnallite and 28.2 vol. $\%$ fluid. 


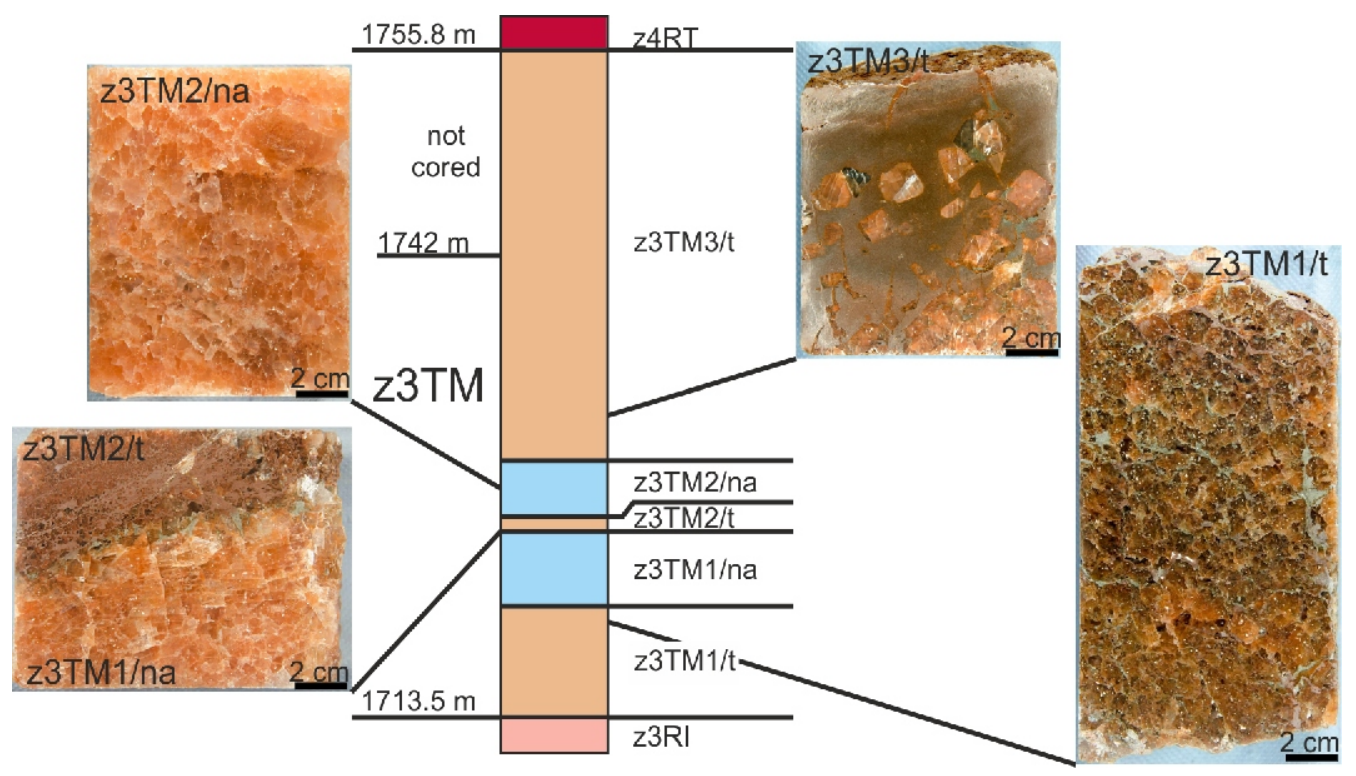

Fig. 4. Schematic profile of the Tonmittelsalz (z3TM) in the Go1004 borehole with photographs of split and polished cores
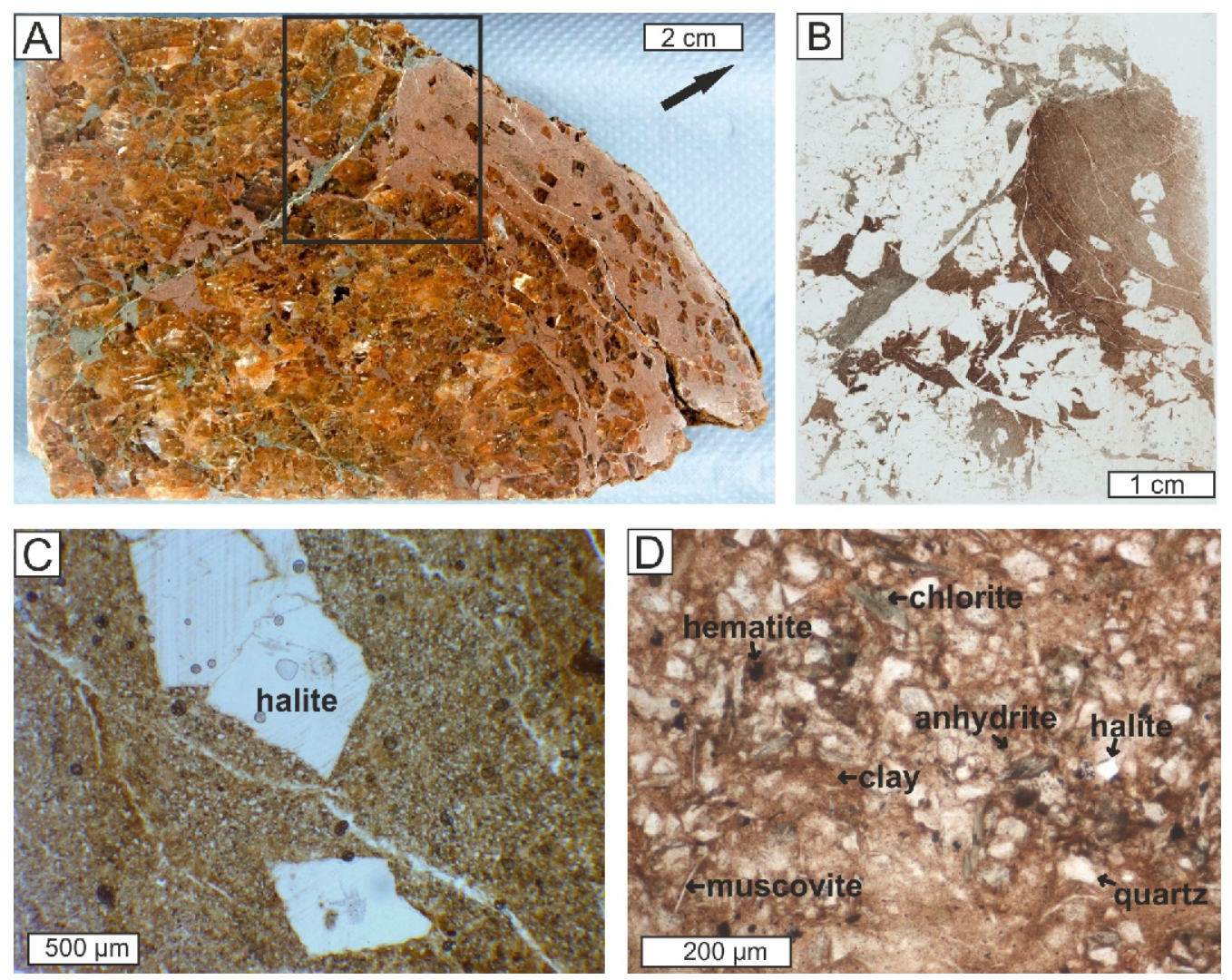

Fig. 5. Macro- and microphotographs in plane polarized light of sample TM25 from the Z3TM2/t subunit

A - split and polished core (1724.70-1724.90 m), arrow points to stratigraphic top; B - detail of (A), thin-section (sample TM25: 1724.83-1724.87 m) showing clay-bearing halite matrix with clay layer fragment on the right hand side including idiomorphic halite crystals; $\mathbf{C}$ - detail of (B), idiomorphic halite crystals in clay-bearing matrix; D - clay-bearing matrix with clay minerals, quartz, anhydrite, halite, muscovite, chlorite and hematite 

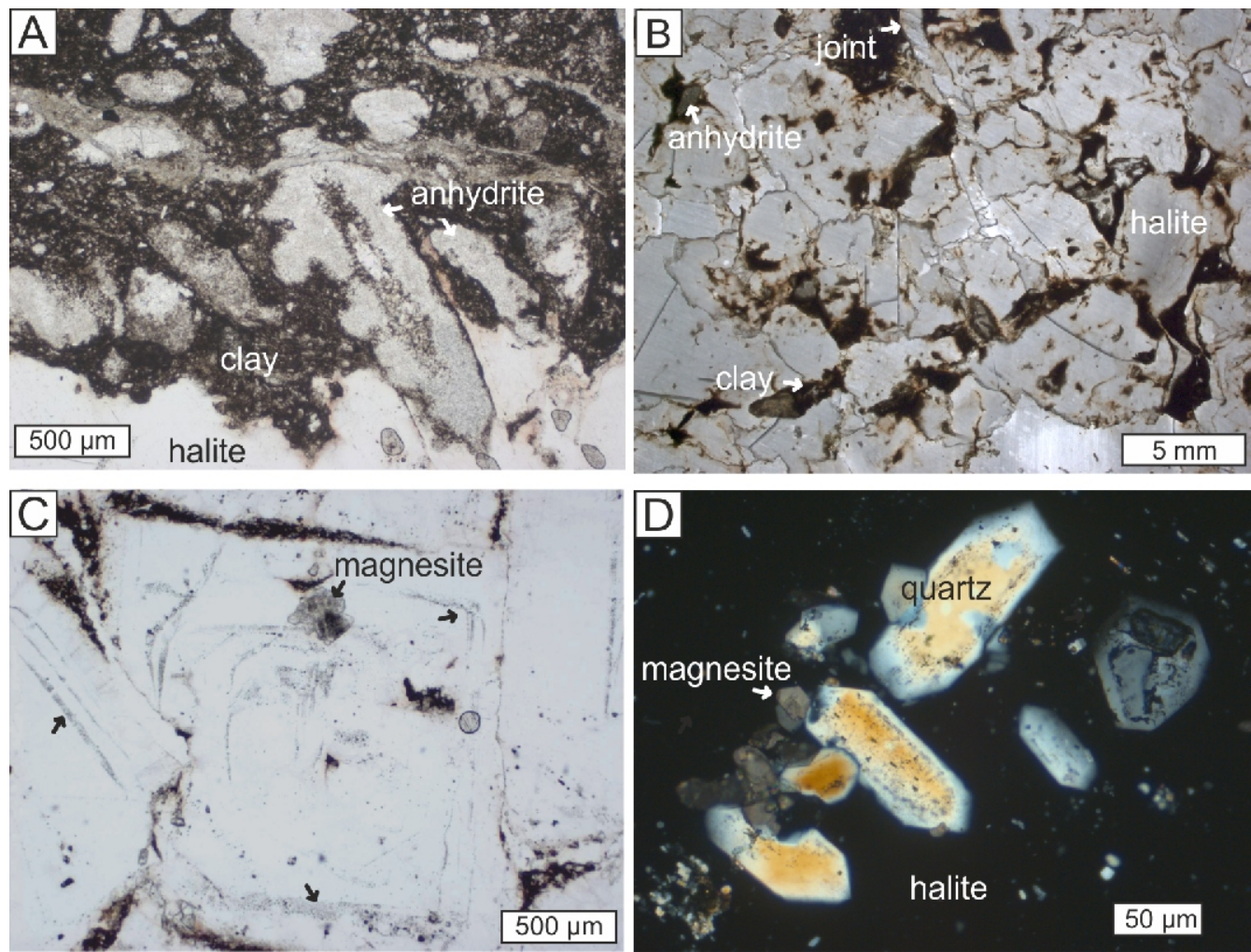

Fig. 6. Microphotographs of samples from z3TM

A - anhydrite aggregates in dark clay matrix; B - halite fabric with clay mainly on grain boundaries and a cross-cutting joint filled with fibrous halite; $\mathbf{C}$ - halite crystals with fluid trails (arrows), magnesite and clay (dark material) on the grain boundaries, z3TM3/t (sample TM29: 1728.64-1728.70 m); D - quartz crystals with fluid inclusion traces and magnesite crystals in a halite matrix; A, B, D: z3TM1/t (sample TM15: $1719.44-1719.50 \mathrm{~m}), \mathrm{A}-\mathrm{C}$ in plane polarized light, D under crossed polars
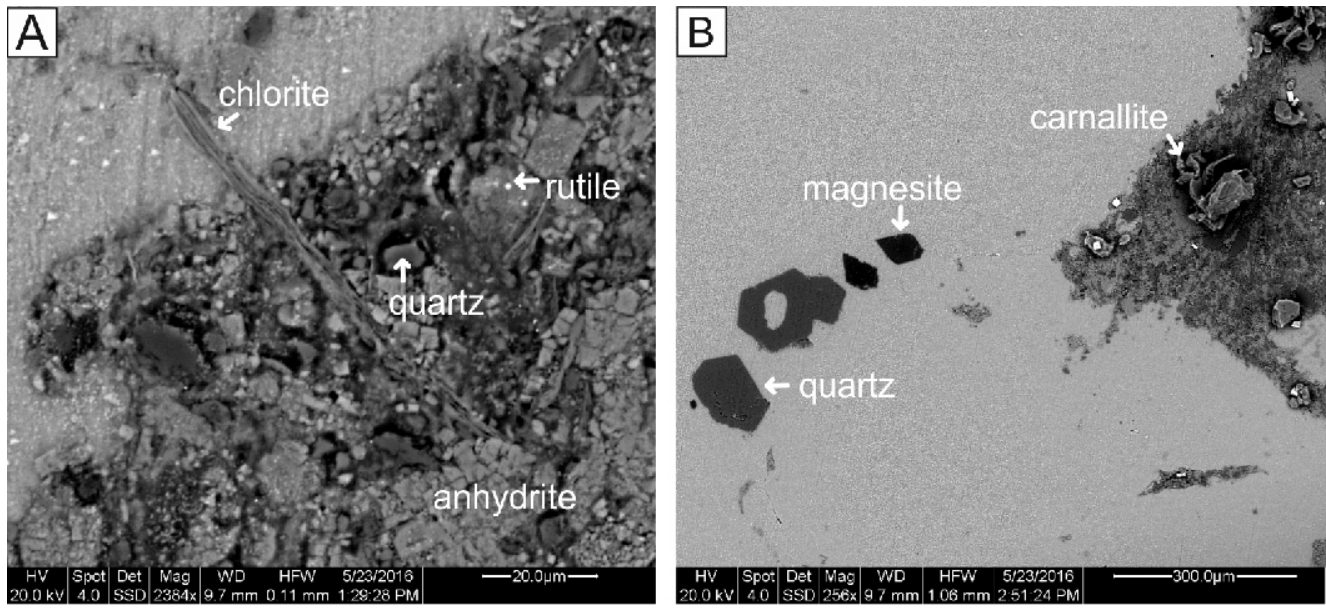

Fig. 7. SEM images of samples from z3TM1/t (sample TM15: 1719.44-1719.50 m)

A - clay-bearing matrix with chlorite, quartz with a dark rim, anhydrite and rutile; B - quartz and magnesite in halite as well as carnallite flakes in a clay-bearing matrix 

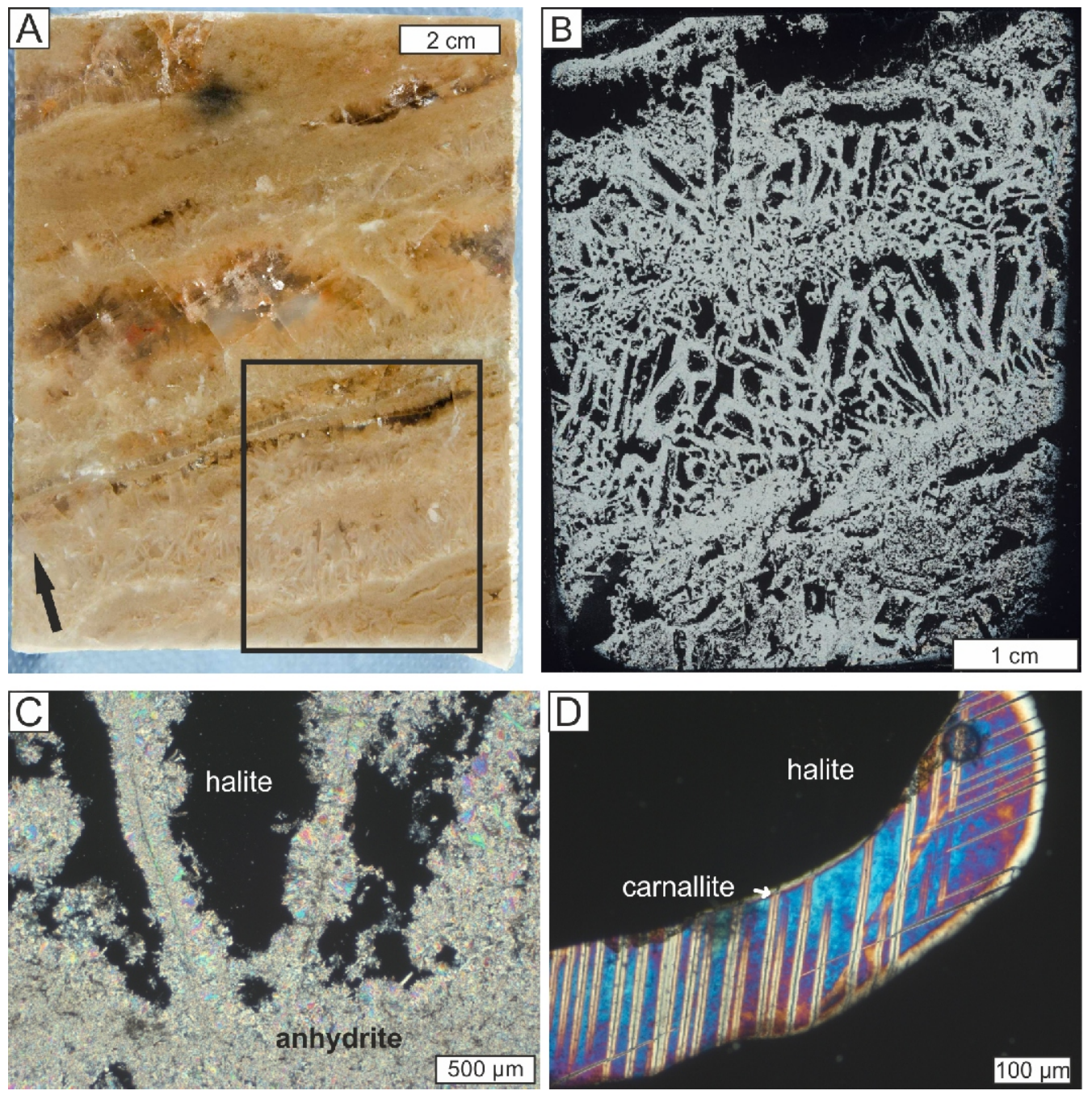

Fig. 8. Anhydrite layer in the halitic subunit z3TM1/na

A - split and polished core, arrow points to stratigraphic top; B - scan of a thin-section (sample TM18: 1720.80-1720.96 m) marked in (A) with crossed polars showing anhydrite crystals (bright) and halite (dark); C - microphotographs of (B) with halite pseudomorphs and anhydrite crystals; $\mathbf{D}$ - microphotographs of carnallite (sample TM16: 1719.80-1719.86 m); B-D under crossed polars
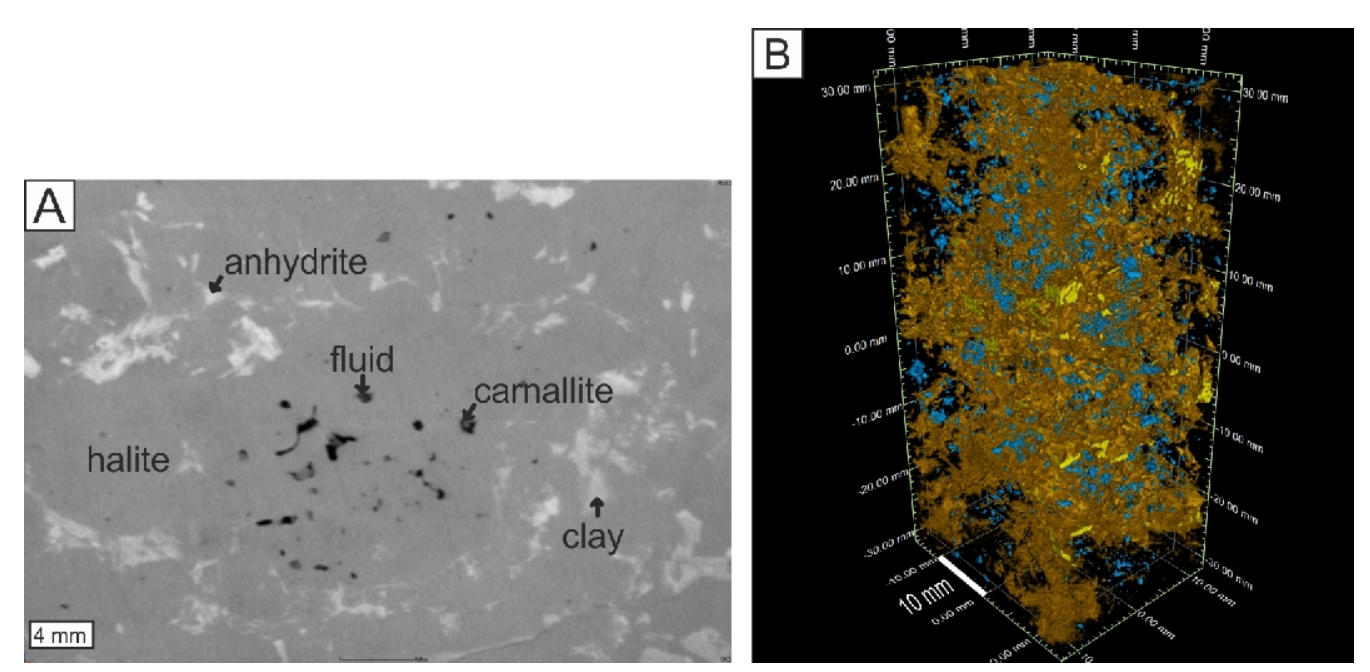

Fig. 9. CT images of samples from the z3TM3/t (sample TM29: 1728.64-1728.70 m)

A - slice image with halite, clay, anhydrite, fluid inclusions and probably carnallite; B - volume body with three phases, brown - clay, yellow - anhydrite, blue - micropores, halite is not displayed 
The halitic subunits (z3TM1/na, z3TM2/na; Fig. 4) between the clay-bearing subunits consist of orange or red, fine to medium grained (1 to $10 \mathrm{~mm}$ in diameter) halite with some clear crystals up to $5 \mathrm{~cm}$ in size. In the lower subunit (z3TM1/na), a $20 \mathrm{~cm}$ thick distinct anhydrite-halite layer with anhydrite needles can be observed (Fig. 8). Halite crystals show pseudomorphism after gypsum crystals with surrounding, perpendicular anhydrite crystals and growth bands between former gypsum crystals. Rarely, polyhalite appears surrounded by anhydrite crystals. The boundaries between the clay-bearing and halitic subunits are very sharp.

\section{GEOCHEMICAL RESULTS FROM THE TONMITTELSALZ}

Based on ICP-OES analyses of 20 samples, the clay-bearing subunits with typically relatively high concentrations of $\mathrm{H}_{2} \mathrm{O}$-insoluble residue (4.4 to 59.4 wt. $\%$ ) show $\mathrm{Mg}$ - and $\mathrm{K}$-concentrations of up to $1 \mathrm{wt} . \%$ (Fig. 10). In halite-dominated subunits, accompanying minerals are rare, except anhydrite with 1 to $7 \mathrm{wt} . \%$ and up to $60 \mathrm{wt} . \%$ in one distinct anhydrite layer between 1720.7 and $1720.9 \mathrm{~m}$ depth (Fig. 8). The bromide concentrations vary in both types between 100 and $300 \mu \mathrm{g} / \mathrm{g}$ halite and show no obvious trend. The $\delta^{34} \mathrm{~S}$ and $\delta^{18} \mathrm{O}$ isotope compositions (Table 2 ) lay between +9.4 to $+10.4 \%$ for $\delta^{34} S$ as well as for $\delta^{18} \mathrm{O}$ and represent typical Zechstein values, which are +9.4 to $+15.5 \%$ or $\delta^{34} S$ and +9.6 to $+12.6 \%$ for $\delta^{18}$ O (Peryt et al.,
2010). The small variation between 9.4 and $10.4 \%$ in both isotope compositions is remarkable (Table 2).

The mineralogical composition of the $\mathrm{H}_{2} \mathrm{O}$-insoluble fraction of three samples was measured by XRD and the Rietveld-method, normalized to 100 wt.\% (Table 3). Samples TM15 and TM26 (geochemical sample TM26 is adjacent to thin-section TM25, see Fig. 5) show a similar mineralogical composition, while sample TM32 is different with a quartz content twice as high as in the other two samples. Additionally, TM32 has no chlorite-smectite mixed layer mineral in the $\mathrm{H}_{2} \mathrm{O}$-insoluble residue and the other phyllosilicate content differs significantly. In TM15 (z3TM1/t subunit) and TM26 (z3TM2/t subunit), the phyllosilicate content accounts for about two-thirds of the insoluble part of the samples, while in TM32, representing the z3TM3/t subunit, a phyllosilicate content of about half of the $\mathrm{H}_{2} \mathrm{O}$-insoluble residue was detected (Table 3 ).

Major and minor components as well as trace elements of seven bulk samples were analysed by ICP-OES and ICP-MS (Table 2) and were plotted on ternary diagrams together with the $\mathrm{H}_{2} \mathrm{O}$-insoluble residue of the z3TM analysed by XRF (Table 2), with the z4TS unit as well as reference samples of Rotliegend salt (Lower Permian) and Zechstein salt-clays.

Rare earth elements (REE) were analysed by ICP-MS and normalized to chondrite (Table 4 and Fig. 11). For normalization, the mean composition of chondrite from Boyton (1984) was used. The REE concentrations are moderately different,

Tonmittelsalz (z3TM)

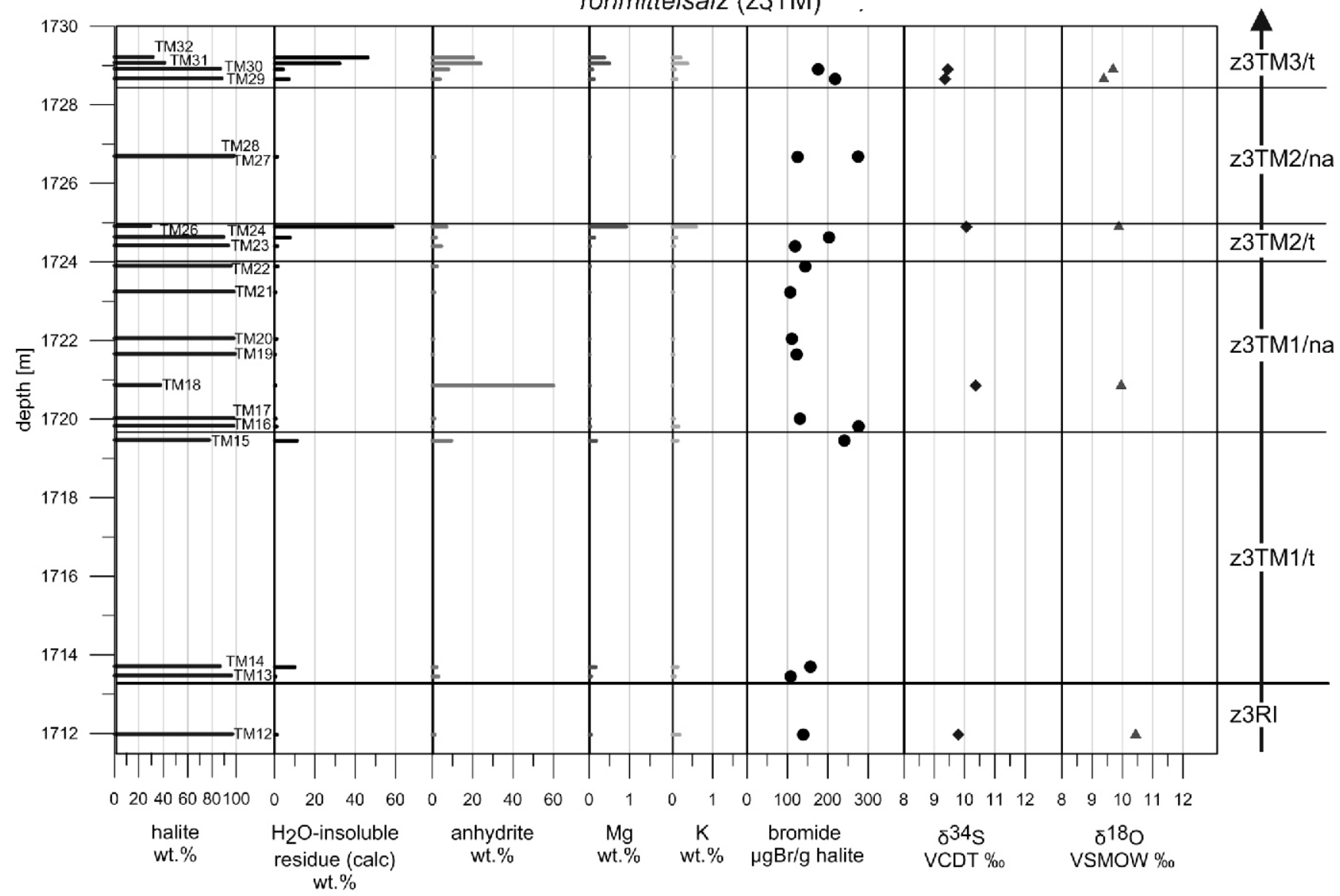

Fig. 10. Calculated quantitative mineralogical composition, Mg-, K-concentrations and bromide contents of the halites, based on ICP-OES analyses as well as isotope compositions of the z3TM subunits 
Major and minor components as well as trace elements of bulk samples and $\mathrm{H}_{2} \mathrm{O}$-insoluble residue samples and $\delta^{34} \mathrm{~S}$ and $\delta^{18} \mathrm{O}$ isotope ratios of samples from Z3TM

\begin{tabular}{|c|c|c|c|c|c|c|c|c|c|}
\hline \multirow{3}{*}{ Samples } & \multicolumn{7}{|c|}{ Bulk samples } & \multicolumn{2}{|c|}{ Anhydrite } \\
\hline & \multirow{2}{*}{ Subunits } & $\mathrm{Al}_{2} \mathrm{O}_{3}$ & $\mathrm{~K}_{2} \mathrm{O}$ & $\mathrm{MgO}$ & $\mathrm{K}$ & $\mathrm{Li}$ & $\mathrm{Rb}$ & $\delta^{34} S$ & $\delta^{18} \mathrm{O}$ \\
\hline & & \multicolumn{3}{|c|}{ wt. $\%$} & \multicolumn{3}{|c|}{$\mu \mathrm{g} / \mathrm{g}$} & VCDT \%o & VSMOW \%o \\
\hline TM15 & z3TM1/t & 1.51 & 0.37 & 1.76 & 3030 & 39 & 10.8 & 9.8 & 10.4 \\
\hline TM18 & z3TM1/na & 0.02 & - & 0.11 & - & 43 & 0.1 & 10.4 & 10 \\
\hline TM24 & z3TM2/t & 1.25 & 0.36 & 1.25 & 2980 & 29 & 10.5 & - & - \\
\hline TM26 & z3TM2/t & 8.22 & 2.11 & 8.51 & 17500 & 161 & 82 & 10.1 & 9.9 \\
\hline TM29 & z3TM3/t & 1.08 & 0.36 & 1.29 & 2980 & 20 & 11.5 & 9.4 & 9.4 \\
\hline TM30 & z3TM3/t & 0.44 & 0.21 & 0.57 & 1780 & 9 & 4.6 & 9.5 & 9.7 \\
\hline TM32 & z3TM3/t & 5.14 & 1.08 & 5.09 & 9000 & 104 & 46 & - & - \\
\hline \multicolumn{5}{|c|}{$\mathrm{H}_{2} \mathrm{O}$-insoluble residue samples } & & & & & \\
\hline TM15 & z3TM1/t & 14.4 & 1.98 & 13.1 & & & & & \\
\hline TM26 & z3TM2/t & 14.9 & 2.20 & 12.6 & & & & & \\
\hline TM32 & z3TM3/t & 10.2 & 1.41 & 8.30 & & & & & \\
\hline
\end{tabular}

Table 3

Mineralogical composition of the $\mathrm{H}_{2} \mathrm{O}$-insoluble residue of three samples of z3TM in wt.\%, normalized to $100 \%$ of $\mathrm{H}_{2} \mathrm{O}$-insoluble residue, phyllosilicates are marked in dark grey

\begin{tabular}{|c|c|c|c|c|c|c|c|c|c|}
\hline Samples & Quartz & Muscovite & Chlorite-smectite & Chlorite & Kaolinite & Microcline & Magnesite & Hematite & $\begin{array}{l}\mathrm{H}_{2} \mathrm{O} \text {-insol. } \\
\text { residue }\end{array}$ \\
\hline TM15 & 27 & 20 & 21 & 13 & 11 & 4 & 3 & $<1$ & 11.2 \\
\hline TM26 & 23 & 20 & 22 & 12 & 12 & 5 & 2 & 2 & 58.6 \\
\hline TM32 & 43 & 15 & 0 & 17 & 17 & 4 & 1 & 2 & 46.2 \\
\hline
\end{tabular}

Total amount of $\mathrm{H}_{2} \mathrm{O}$-insoluble residue of bulk sample for comparison

Table 4

Rare earth elements of the $\mathrm{H}_{2} \mathrm{O}$-insoluble residue of the z3TM subunits, normalized to chondrites according to Boyton (1984)

\begin{tabular}{|l|c|c|c|c|c|c|c|c|}
\hline \multirow{2}{*}{$\begin{array}{c}\text { Rare earth } \\
\text { elements } \\
(\mathrm{REE})\end{array}$} & \multicolumn{9}{|c|}{ Samples (normalized to chondrite) } \\
\cline { 2 - 10 } & Subunits & z3TM1/t & z3TM1/na & \multicolumn{2}{|c|}{ z3TM2/t } & \multicolumn{3}{c|}{ z3TM3/t } \\
\cline { 2 - 10 } & Chondrite & TM15 & TM18 & TM24 & TM26 & TM29 & TM30 & TM32 \\
\hline $\mathrm{La}$ & 0.31 & 16.48 & 0.58 & 13.94 & 72.27 & 10.29 & 3.95 & 79.1 \\
\hline $\mathrm{Ce}$ & 0.808 & 12.84 & 0.39 & 10.81 & 55.26 & 7.79 & 2.92 & 61.88 \\
\hline $\mathrm{Pr}$ & 0.122 & 10 & 0.28 & 8.55 & 41.65 & 5.88 & 2.28 & 47.76 \\
\hline $\mathrm{Nd}$ & 0.6 & 7.57 & 0.24 & 6.38 & 30.73 & 4.44 & 1.66 & 36.22 \\
\hline $\mathrm{Sm}$ & 0.195 & 4.52 & 0.18 & 3.4 & 16.79 & 2.52 & 1 & 20.38 \\
\hline $\mathrm{Eu}$ & 0.0735 & 1.97 & 0.09 & 1.47 & 8.07 & 1.25 & 0.55 & 8.37 \\
\hline $\mathrm{Gd}$ & 0.259 & 2.8 & 0.12 & 2.25 & 10.77 & 1.63 & 0.69 & 12.62 \\
\hline $\mathrm{Tb}$ & 0.0474 & 1.92 & 0.08 & 1.46 & 7.64 & 1.16 & 0.51 & 8.5 \\
\hline $\mathrm{Dy}$ & 0.322 & 1.62 & 0.07 & 1.18 & 6.68 & 1.01 & 0.41 & 6.95 \\
\hline $\mathrm{Ho}$ & 0.0718 & 1.33 & 0.05 & 0.98 & 5.65 & 0.84 & 0.37 & 5.35 \\
\hline $\mathrm{Er}$ & 0.21 & 1.29 & 0.04 & 0.89 & 5.58 & 0.84 & 0.36 & 5.12 \\
\hline $\mathrm{Tm}$ & 0.0324 & 1.19 & 0.04 & 0.78 & 5.32 & 0.68 & 0.3 & 4.7 \\
\hline $\mathrm{Yb}$ & 0.209 & 1.27 & 0.04 & 0.85 & 5.73 & 0.79 & 0.34 & 5.28 \\
\hline $\mathrm{Lu}$ & 0.0322 & 1.2 & 0.03 & 0.78 & 5.24 & 0.7 & 0.28 & 4.89 \\
\hline $\mathrm{H}$ & & 11.2 & 0.5 & 7.6 & 58.6 & 7.1 & 4.3 & 46.2 \\
\hline
\end{tabular}

For comparison, $\mathrm{H}_{2} \mathrm{O}$-insoluble residue amount in last row 


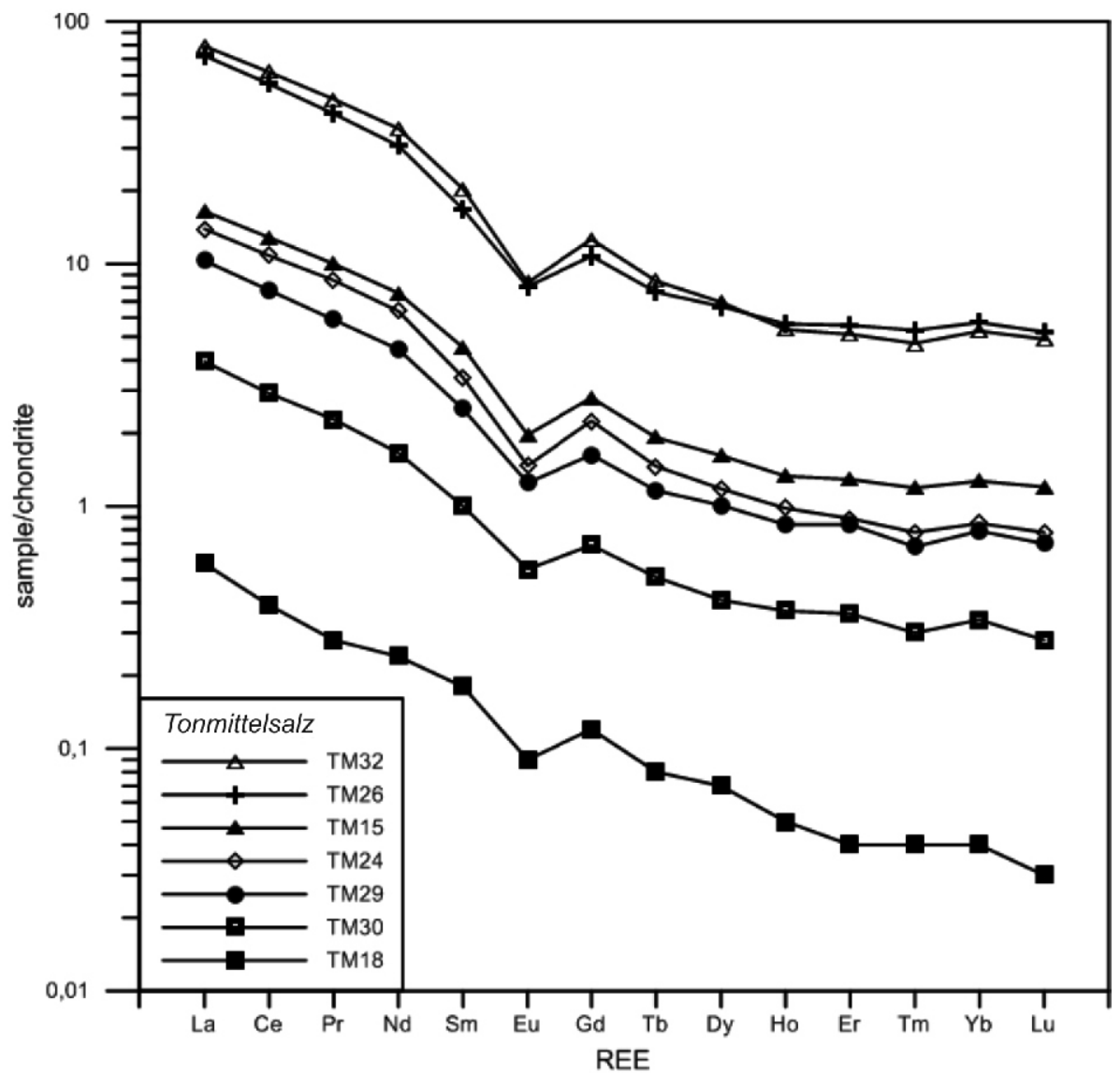

Fig. 11. Rare earth element distribution in subunits of the Z3TM, normalized to chondrite (for explanation of samples see Table 4)

but the REE patterns do not change significantly. As documented in Table 4 and Figure 11, it is possible to define specific groups of samples. The lowest REE concentrations $(<0.6$, in chondrite normalization) were detected in the z3TM1/na subunit (sample TM18), another group shows values between $<4$ to $<17$ (subunits: z3TM1/t, z3TM2/t and z3TM3/t) and the highest values were determined in the z3TM2/t and z3TM3/t subunit (samples TM26 and TM32). A negative Eu anomaly can be observed in all samples.

\section{PETROGRAPHIC STUDIES OF THE TONBROCKENSALZ}

The Tonbrockensalz (z4TS) unit was encountered twice in the deep borehole Go1004. The z4TS (Fig. 12) is divided into a lower subunit (z4TSU) and an upper subunit (z4TSO). Mineralogical and geochemical studies were performed on samples from depths between 1803.5 and $1825.5 \mathrm{~m}$. The normal thickness of this unit is $\sim 15 \mathrm{~m}$ (Bornemann et al., 2008). The z4TSU lies on two fold limbs in this section: the upper limb between 1803.5 and $1809.5 \mathrm{~m}$ and the lower limb between 1820.8 and $1825.5 \mathrm{~m}$, while the uppermost part of Z4TSO is located within the hinge zone at approximately $1815 \mathrm{~m}$.

The lower subunit (z4TSU) of the Tonbrockensalz (Fig. 12) consists of brown clay-bearing rock salt with a clay/anhydrite content of approximately $10 \%$ at the bottom and top. The layer in between two clay-bearing layers is characterized by an orange halitic rock salt with less than $5 \%$ of impurities. The boundaries between these layers appear gradational. In the clay-bearing layers, halite crystals of sizes of up to $2 \mathrm{~cm}$ are em- bedded in indistinct layers. Red-brown or grey clay occurs as thin bands, as clasts up to $2 \mathrm{~cm}$ in size with anhydrite or as coats around halite crystals. The halite matrix is fine-grained $(0.5-3 \mathrm{~mm})$ with halite crystals in sizes up to $5 \mathrm{~cm}$. The halite fabric shows commonly smoothly curved grain boundaries, which tend to build up $120^{\circ}$ triple junctions with many fluid inclusions as pockets or channels on the grain boundaries (Fig. 13A). Fluid inclusions within halite crystals occasionally show negative crystal shapes (Fig. 13B). Embedded in a halite matrix, anhydrite aggregates consist of up to $300 \mu \mathrm{m}$ (hyp)-idiomorphic crystals together with polyhalite and are commonly surrounded by a rim of clay (Fig. 13E, F). Some carnallite is present as well (Fig. 13D). In the clay-bearing matrix, predominantly rounded quartz and columnar anhydrite, both with grain sizes of 50 to $100 \mu \mathrm{m}$, are common, as well as clay minerals, chlorite, muscovite, celestine and hematite, all with grain sizes $<25 \mu \mathrm{m}$ (Fig. 13C).

The upper subunit (z4TSO) of the Tonbrockensalz (Fig. 12) is represented by an orange rock salt with a brecciated fabric of halite and clay-bearing clasts up to $5 \mathrm{~cm}$ in size embedded in a halite matrix with carnallite nests. Several veins with fibrous halite cross-cut the rocks. The halite matrix shows commonly elongated halite crystals with curved to straight grain boundaries, which tend to build up $120^{\circ}$ triple junctions (Fig. 14A). Clay sits on halite grain boundaries and is associated with anhydrite in layers and aggregates. The clay consists of very fine-grained components (clay minerals, phyllosilicates and quartz) as well as columnar shaped (>100 $\mu \mathrm{m})$ anhydrite crystals, which are locally oriented roughly parallel to and around 


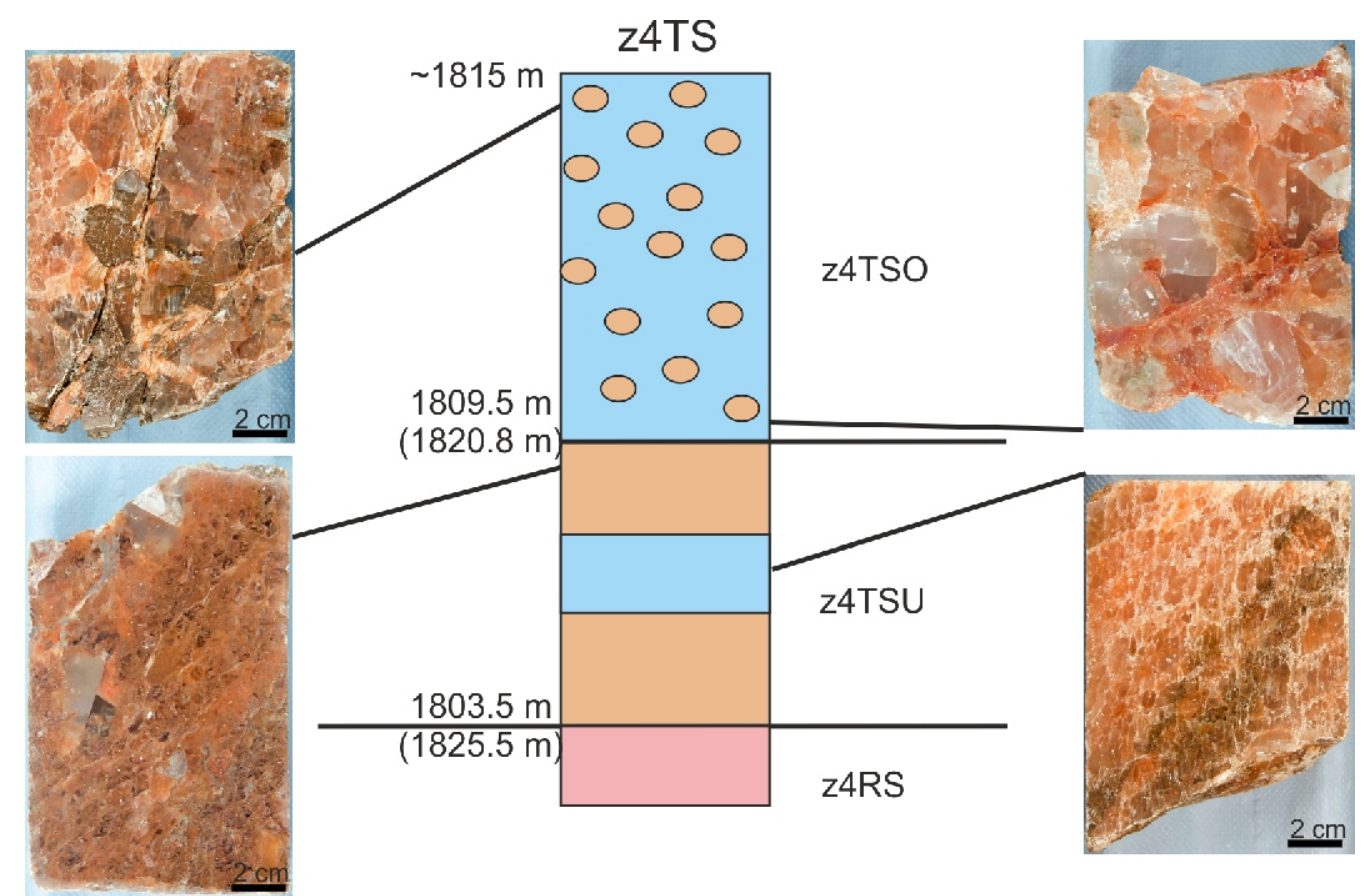

Fig. 12. Schematic profile of the z4TS in the G01004 borehole with photographs of split and polished cores

halite crystals (Fig. 14B), and polyhalite crystals. Clay-bearing clasts of sizes up to a few $\mathrm{cm}$ with cross-cutting veins with fibrous halite are surrounded by halite matrix. These clasts show an internal fabric of clasts in a brecciated clay-bearing fabric as well as bedding defined by quartz and anhydrite crystals (Fig. 14D). Folded anhydrite layers occur with clay clasts (Fig. 14C).

Celestine and zircon were detected by SEM (Fig. 15). Under the CT, clay mineral coatings of hypidiomorphic halite crystals in a halite matrix and an aligned orientation of clasts accompanied with fluid-filled pores and fissures, which were generated during sample preparation, were observed (Fig. 16).

\section{GEOCHEMICAL RESULTS FROM THE TONBROCKENSALZ}

The Tonbrockensalz unit comprises two subunits: a lower subunit (z4TSU) and upper subunit (z4TSO). Based on ICP-OES data of 34 samples, the mineralogical compositions of the z4TSU and z4TSO subunits are similar (Fig. 17). Halite represents the main component with average amounts of $89 \mathrm{wt} . \%$ in the upper fold limb of z4TSU between 1803.5 and $1809.5 \mathrm{~m}, 91 \mathrm{wt} \%$ in the lower fold limb of z4TSU at 1820.8 to $1825.5 \mathrm{~m}$ as well as $92 \mathrm{wt} . \%$ in z4TSO. A higher anhydrite content (up to $20 \mathrm{wt} . \%$ ) is noticeable in the upper fold limb z4TSU section, in contrast to the corresponding lower fold limb with anhydrite contents of up to $7 \mathrm{wt} \%$, while a low Mg- and K-content of up to $0.4 \mathrm{w} \%$ was determined in both parts.

The bromide content shows a weak trend, increasing from $\sim 70 \mu \mathrm{g} / \mathrm{g}$ halite in the upper fold limb of Z4TSU to the maximum of $250 \mu \mathrm{g} / \mathrm{g}$ halite at the bottom of z4TSO, followed by a decrease in $\mathrm{Br}$ content towards the middle part of Z4TSO, which is the stratigraphic highest part, and the rest of the data set is fairly mirrored and repeated.

The $\delta^{34} \mathrm{~S}$ isotope values show a slight overall decrease from 9.7 to $9.3 \%$ from bottom to top within z4TSU, the $\delta^{18} \mathrm{O}$ values vary between 8.8 and $10 \%$ (Table 5 ). The $\delta^{34} S$ values of
z4TSO are relatively low ( 9\%). Compared to z4TSU, the $\delta^{18} \mathrm{O}$ values in Z4TSO are more variable between 8.5 and $11.9 \%$.

XRD and Rietveld-method performed on the $\mathrm{H}_{2} \mathrm{O}$-insoluble residue of three samples of the Z4TS (Table 6) show predominantly similar results as for the z3TM (Table 3). Major components are quartz, muscovite and chlorite-smectite mixed layer mineral (all $\sim 20 \mathrm{wt} . \%$ ) with minor amounts around $\sim 10 \mathrm{wt} . \%$ of chlorite and kaolinite as well as accessory amounts of magnesite, microcline and hematite. Phyllosilicates are the prevalent mineral group with $\sim 2 / 3$ to $3 / 5$ of the mineral content of the $\mathrm{H}_{2} \mathrm{O}$-insoluble residue.

Major and minor components as well as trace elements were analysed of five bulk rock samples by ICP-OES and ICP-MS (Table 5). These samples were plotted on ternary diagrams together with three samples of $\mathrm{H}_{2} \mathrm{O}$-insoluble residues of z4TS (Table 5) and z3TM samples as well as reference samples of Rotliegend salt (Lower Permian) and Zechstein salt-clays (Fig. 19).

Rare earth elements were detected by ICP-MS and normalized to chondrite (Table 7 and Fig. 18). For normalization, mean composition of chondrites was used from Boyton (1984). With the exception of TS38, all samples show a similar REE concentration between 5.7 and 15.8 for La to $0.4-1.1$ for $L u$. A negative Eu anomaly can be observed in all samples taken from z4TSU.

\section{INTERPRETATION AND COMPARATIVE DISCUSSION}

The Tonmittelsalz and Tonbrockensalz units show a couple of common characteristic features. However, some features are unique for the individual unit and can be used as a "fingerprint".

Both lithostratigraphic units are dominated by halite, but with $\sim 79$ wt. $\%$ the mean amount in the z3TM is lower than in the z4TS with $\sim 91$ wt. \% (Table 8). Anhydrite and $\mathrm{H}_{2} \mathrm{O}$-insoluble res- 

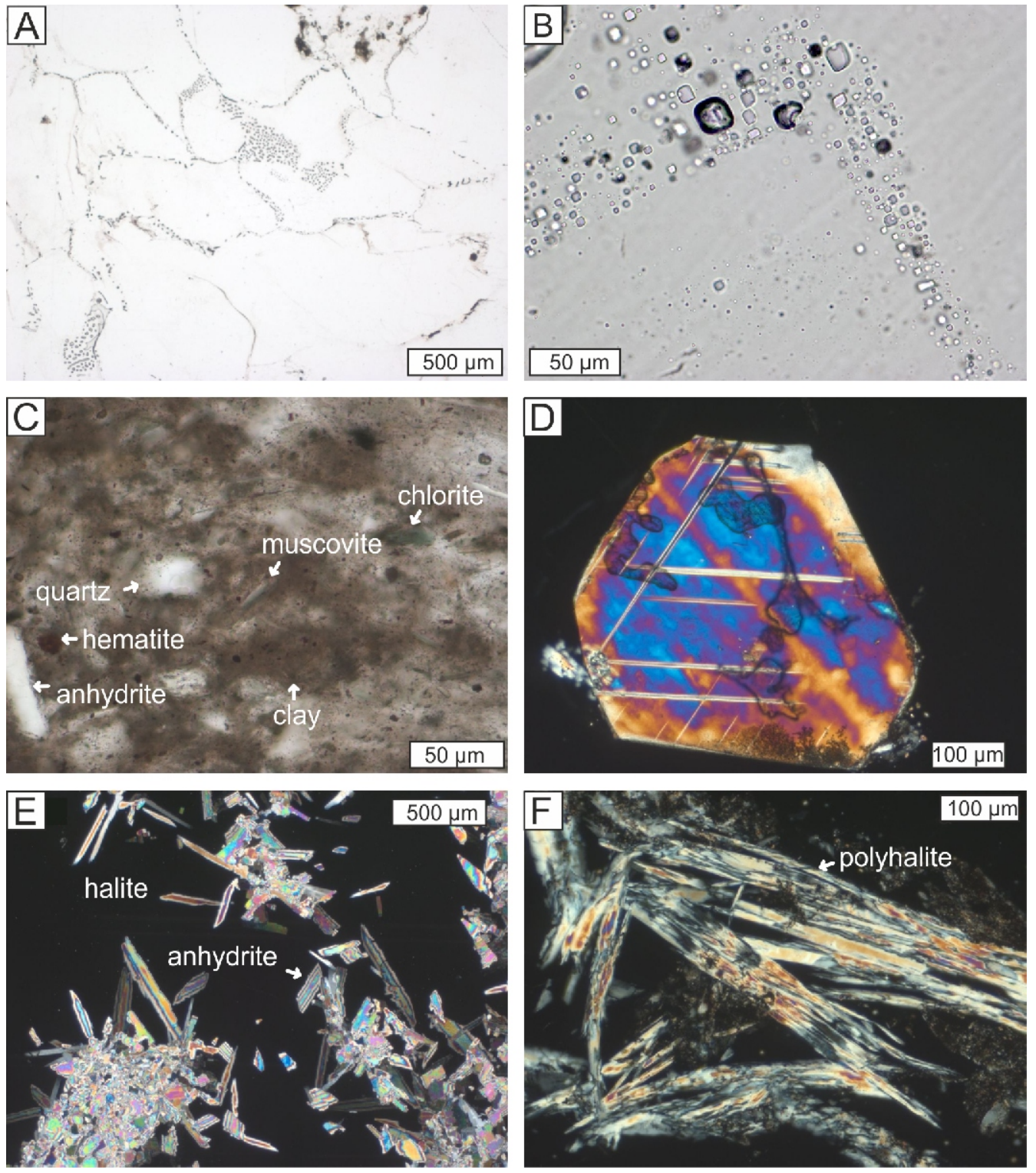

Fig. 13. Microphotographs of samples of z4TSU

A - halite crystals with fluid inclusions (grey areas) at grain boundaries (sample TS35: 1805.12-1805.17 m); B - fluid inclusions with negative crystal shapes (sample TS34: 1804.68-1804.72 m); C - clay matrix with chlorite, anhydrite, muscovite, quartz and hematite (sample TS33: 1803.50-1803.54 m); D - idiomorphic carnallite crystal (sample TS35: 1805.12-1805.17 m); E - anhydrite crystals in halite (sample TS40: 1808.33-1808.39 m); F - polyhalite crystals (sample TS59: 1820.94-1820.99 m); A-C in plane polarized light, D-F under crossed polars 

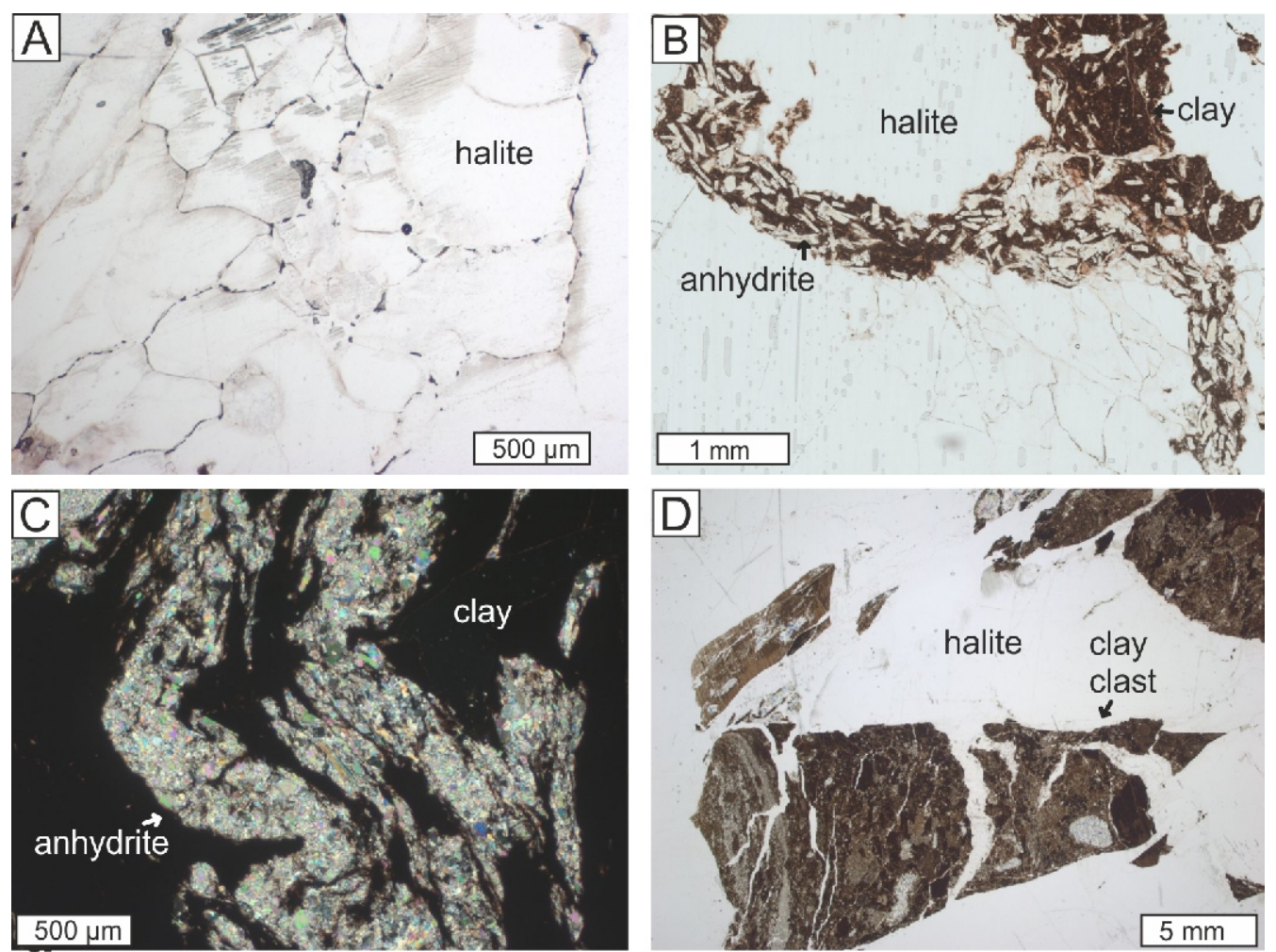

Fig. 14. Microphotographs of samples from the z4TSO

A - halite fabric (sample TS50: 1814.46-1814.52 m); B - anhydrite crystals in a clay-matrix next oriented roughly parallel to halite crystals (sample TS44: $1809.74-1809.80 \mathrm{~m}$ ); C - folded anhydrite layer in clay matrix (sample TS52: 1814.95-1815.01 m); D - clay clasts in halite matrix (sample TS49: 1814.30-1814.36 m); $A, B, D$ under crossed polars, $C$ in plane polarized light
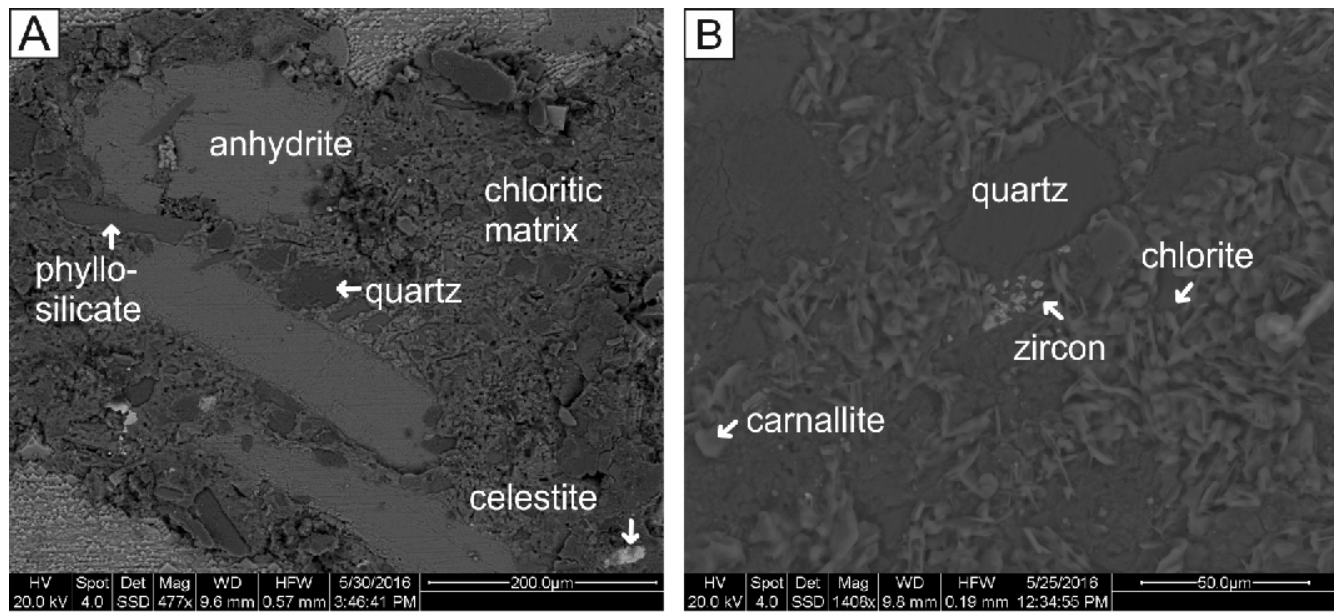

Fig. 15. SEM images of samples from the z4TS

A - chloritic matrix with anhydrite, quartz, phyllosilicates and celestine (z4TSO, sample TS44: 1809.74-1809.80 m); B - matrix with quartz, chlorite, carnallite and zircon (z4TSU, sample TS33: 1803.50-1803.54 m) 


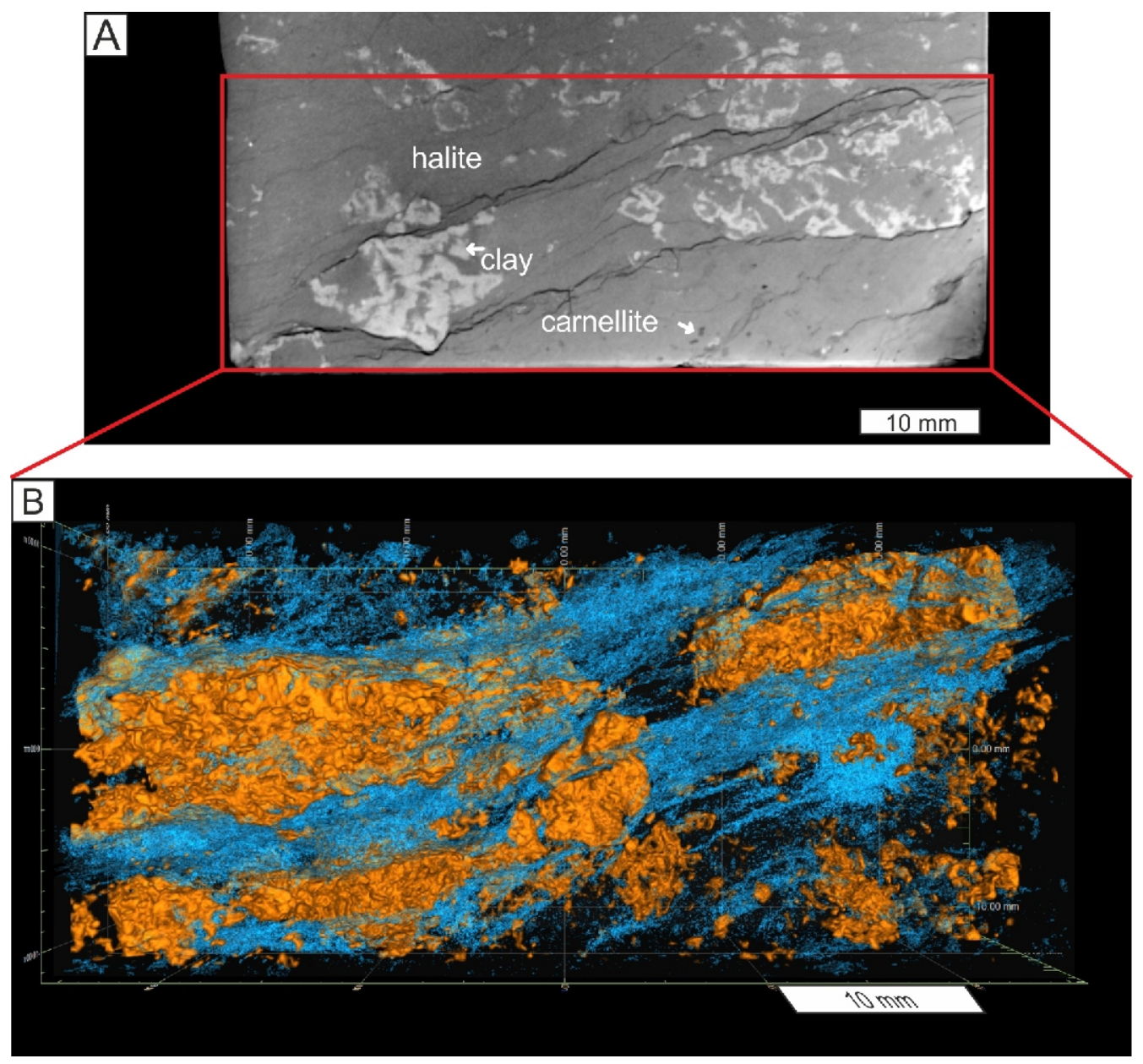

Fig. 16. CT images of samples from the z4TSU (sample TS70: 1824.00-1824.05 m)

A - slice image showing clay around halite crystals and probably carnallite in a halite matrix, with joints and pores caused by sample preparation; B - volume body of the sample with insoluble residue (orange), pores and fractures (blue); halite is not displayed

Table 5

Major and minor components as well as trace elements of bulk samples and $\mathrm{H}_{2} \mathrm{O}$-insoluble residue samples and $\delta^{34} \mathrm{~S}$ and $\delta^{18} \mathrm{O}$ isotope compositions of samples from the z4TS

\begin{tabular}{|c|c|c|c|c|c|c|c|c|c|}
\hline \multirow{3}{*}{ Samples } & \multicolumn{7}{|c|}{ Bulk samples } & \multicolumn{2}{|c|}{ Anhydrite } \\
\hline & \multirow{2}{*}{ Subunits } & $\mathrm{Al}_{2} \mathrm{O}_{3}$ & $\mathrm{~K}_{2} \mathrm{O}$ & $\mathrm{MgO}$ & $\mathrm{K}$ & $\mathrm{Li}$ & $\mathrm{Rb}$ & \multirow{2}{*}{$\frac{\delta^{34} S}{\text { VCDT } \% o}$} & \multirow{2}{*}{$\frac{\delta^{18} \mathrm{O}}{\mathrm{VSMOW} \%}$} \\
\hline & & \multicolumn{3}{|c|}{ wt. $\%$} & \multicolumn{3}{|c|}{$\mu \mathrm{g} / \mathrm{g}$} & & \\
\hline TS33 & z4TSU & 0.78 & 0.33 & 0.79 & 2780 & 12 & 7.5 & 9.7 & 9.9 \\
\hline TS38 & z4TSU & 0.03 & 0.16 & 0.07 & 1290 & 1 & 0.5 & 9.6 & 8.8 \\
\hline TS40 & z4TSU & 0.53 & 0.26 & 0.59 & 2140 & 8 & 5.2 & 9.3 & 10 \\
\hline TS44 & z4TSO & 1.54 & 0.62 & 1.56 & 5130 & 20 & 14.1 & 9.1 & 8.5 \\
\hline TS49 & z4TSO & 1.10 & 0.46 & 1.28 & 3840 & 15 & 10.7 & 9 & 11.9 \\
\hline
\end{tabular}

$\mathrm{H}_{2} \mathrm{O}$-insoluble residue samples

\begin{tabular}{|l|l|l|l|l|}
\hline TS33 & z4TSU & 15.2 & 3.12 & 12.2 \\
\hline TS44 & z4TSO & 15.2 & 3.85 & 10.5 \\
\hline TS70 & z4TSU & 14.6 & 2.92 & 13.0 \\
\hline
\end{tabular}


Tonbrockensalz (z4TS)

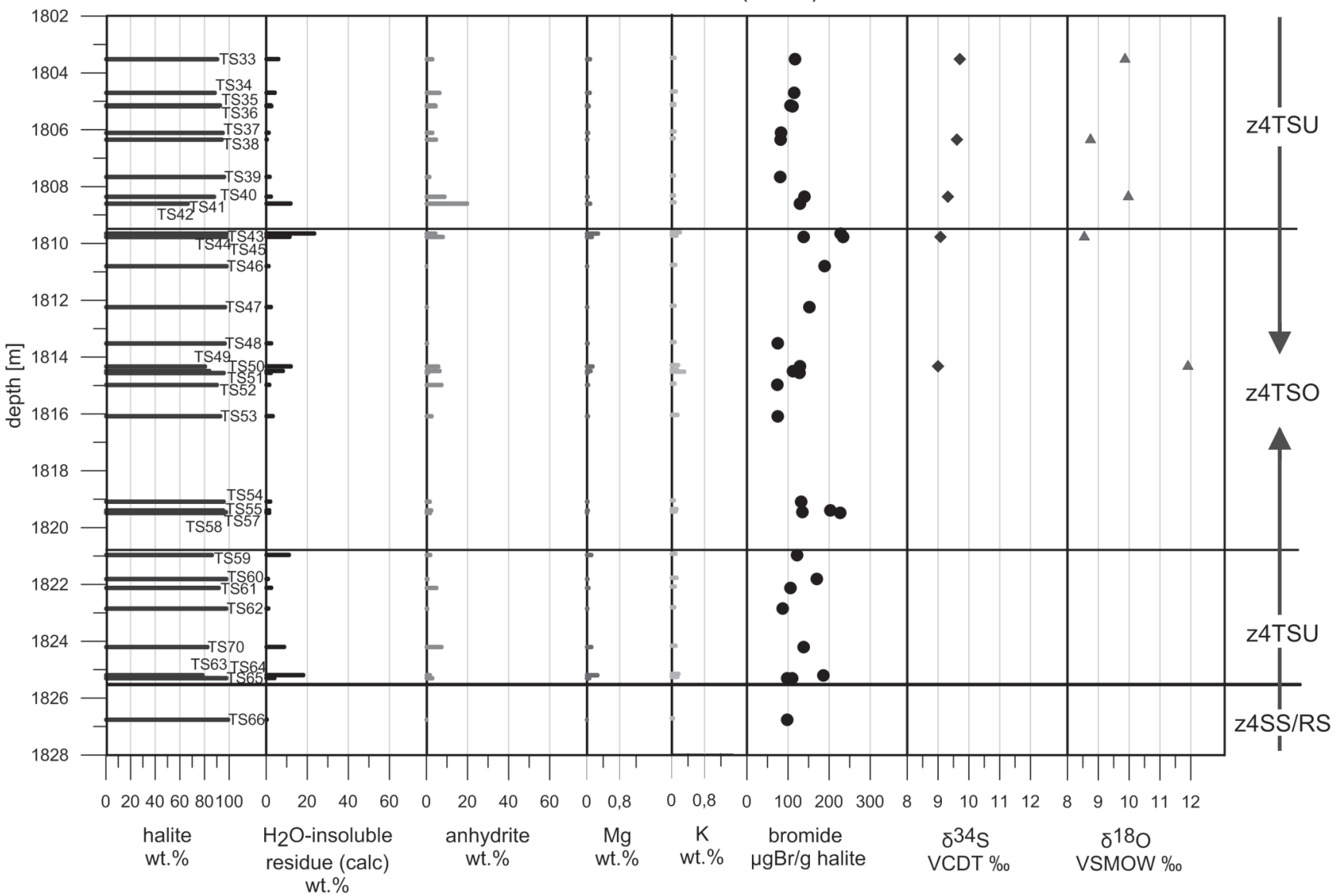

Fig. 17. Calculated quantitative mineralogical composition, Mg-, K-concentrations and bromide contents of the halites, based on ICP-OES analyses as well as isotope compositions of Z4TS subunits

Sample positions are in the halite column, arrows point to the stratigraphic top

Table 6

Mineralogical composition of the $\mathrm{H}_{2} \mathrm{O}$-insoluble residue of three samples of the $\mathrm{z} 4 \mathrm{TS}$ in wt.\%, normalized to $100 \%$ of $\mathrm{H}_{2} \mathrm{O}$-insoluble residue, phyllosilicates are marked in dark grey

\begin{tabular}{|l|c|c|c|c|c|c|c|c|c|}
\hline Samples & Quartz & Muscovite & Chlorite-smectite & Chlorite & Kaolinite & Microcline & Magnesite & Hematite & $\begin{array}{c}\mathrm{H}_{2} \mathrm{O} \text {-insol. } \\
\text { residue }\end{array}$ \\
\hline TS33 & 20 & 21 & 24 & 12 & 11 & 7 & 2 & 3 & 6.0 \\
\hline TS44 & 22 & 21 & 19 & 11 & 9 & 11 & 4 & 3 & 11.5 \\
\hline TS70 & 21 & 21 & 21 & 13 & 10 & 7 & 3 & 3 & 8.9 \\
\hline
\end{tabular}

Total amount of $\mathrm{H}_{2} \mathrm{O}$-insoluble residue of bulk samples for comparison 
Table 7

Rare earth elements of samples from the z4TS, normalized to chondrites according to Boyton (1984)

\begin{tabular}{|l|l|l|l|l|l|c|}
\hline \multirow{2}{*}{$\begin{array}{c}\text { Rare earth } \\
\text { elements } \\
\text { (REE) }\end{array}$} & \multicolumn{6}{|c|}{ Samples (normalized to chondrite) } \\
\cline { 2 - 7 } & Subunits & z4TSU & z4TSU & z4TSU & z4TSO & z4TSO \\
\cline { 2 - 7 } & Chondrite & TS33 & TS38 & TS40 & TS44 & TS49 \\
\hline $\mathrm{Ce}$ & 0.31 & 7.52 & 0.29 & 5.7 & 15.79 & 8.79 \\
\hline $\mathrm{Pr}$ & 0.808 & 5.69 & 0.18 & 4.47 & 11.99 & 6.66 \\
\hline $\mathrm{Nd}$ & 0.122 & 4.55 & 0.14 & 3.46 & 9.12 & 5.13 \\
\hline $\mathrm{Sm}$ & 0.6 & 3.28 & 0.11 & 2.64 & 6.82 & 3.93 \\
\hline $\mathrm{Eu}$ & 0.195 & 1.91 & 0.05 & 1.59 & 3.88 & 2.25 \\
\hline $\mathrm{Gd}$ & 0.0735 & 0.97 & 0.04 & 0.8 & 1.72 & 1.15 \\
\hline $\mathrm{Tb}$ & 0.259 & 1.69 & 0.07 & 1.11 & 2.48 & 1.5 \\
\hline $\mathrm{Dy}$ & 0.0474 & 0.87 & 0.04 & 0.77 & 1.71 & 1.07 \\
\hline $\mathrm{Ho}$ & 0.322 & 0.73 & 0.03 & 0.57 & 1.45 & 0.97 \\
\hline $\mathrm{Er}$ & 0.0718 & 0.61 & 0.03 & 0.48 & 1.22 & 0.89 \\
\hline $\mathrm{Tm}$ & 0.21 & 0.58 & 0.03 & 0.44 & 1.22 & 0.85 \\
\hline $\mathrm{Yb}$ & 0.0324 & 0.5 & 0.03 & 0.36 & 1.11 & 0.7 \\
\hline $\mathrm{Lu}$ & 0.209 & 0.56 & 0.04 & 0.43 & 1.17 & 0.8 \\
\hline $\mathrm{H} \mathrm{H}_{2} \mathrm{O}-$-insoluble \\
$($ wt.\%)
\end{tabular}

For comparison, $\mathrm{H}_{2} \mathrm{O}$-insoluble residue amount in last row

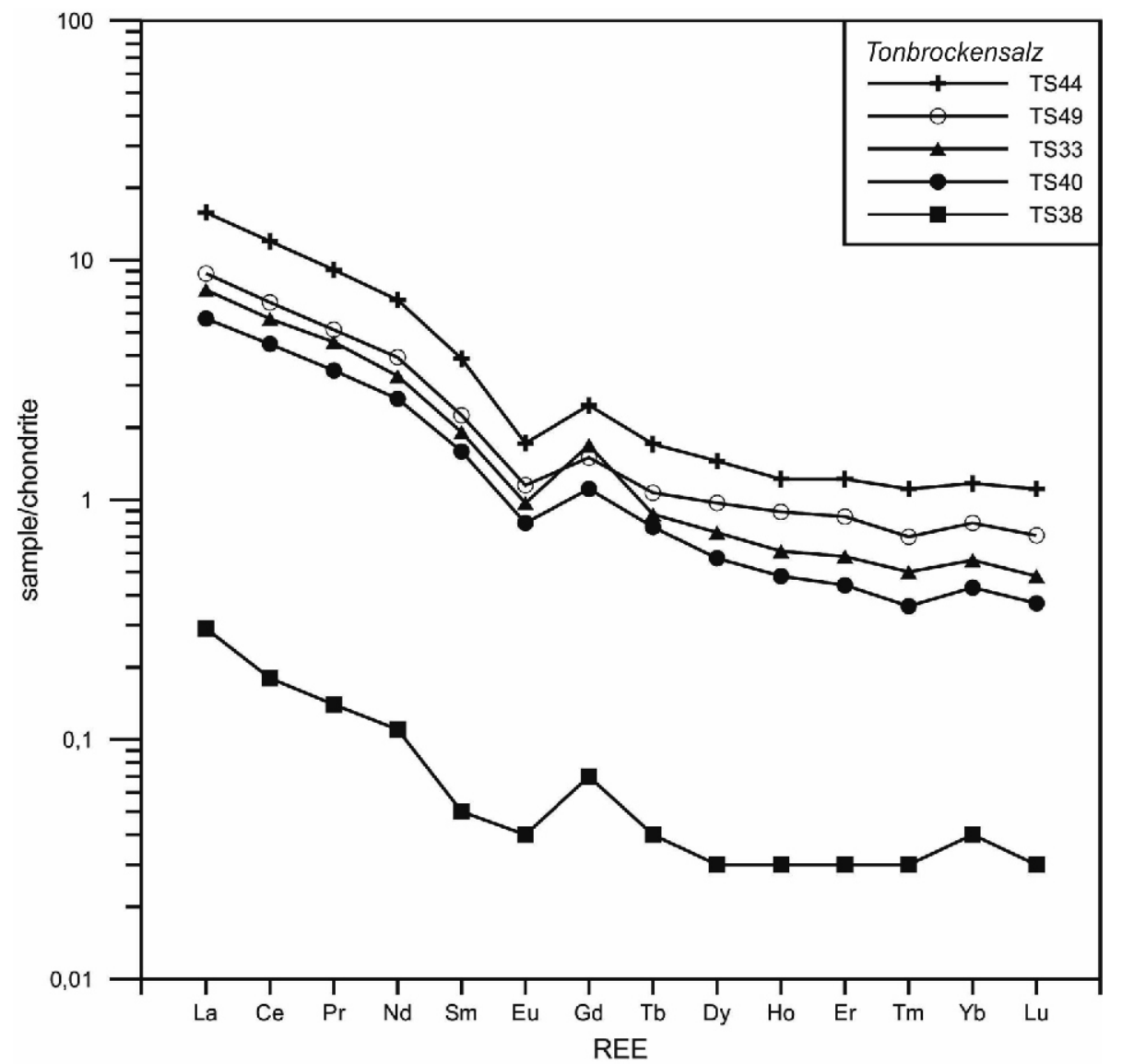

Fig. 18. Rare earth element distribution of bulk rock samples from the z4TS, normalized to chondrite (for explanation of samples see Table 7) 
Mean amounts of $\mathrm{H}_{2} \mathrm{O}$-soluble components (in wt.\%) of subunits and overall (in bold) of the z3TM and z4TS, based on ICP-OES; decimal places from the applied calculation method document only a trend

\begin{tabular}{|c|c|c|c|c|c|c|c|c|c|}
\hline \multicolumn{6}{|c|}{ Subunits } & Unit & \multicolumn{2}{|c|}{ Subunits } & Unit \\
\hline Components & z3TM3/t & z3TM2/na & z3TM2/t & z3TM1/na & z3TM1/t & Z3TM & z4TSO & zUTSU & z4TS \\
\hline Halite & 61.8 & 97.9 & 59.4 & 88.5 & 89.6 & 79.0 & 91.6 & 90.6 & 90.5 \\
\hline Anhydrite & 14.0 & 0.7 & 4.5 & 10.0 & 3.8 & 6.6 & 2.8 & 2.6 & 3.9 \\
\hline $\mathrm{H}_{2} \mathrm{O}$-insol. residue & 22.5 & 1.2 & 22.6 & 0.8 & 7.3 & 9.9 & 3.6 & 5.8 & 4.8 \\
\hline
\end{tabular}

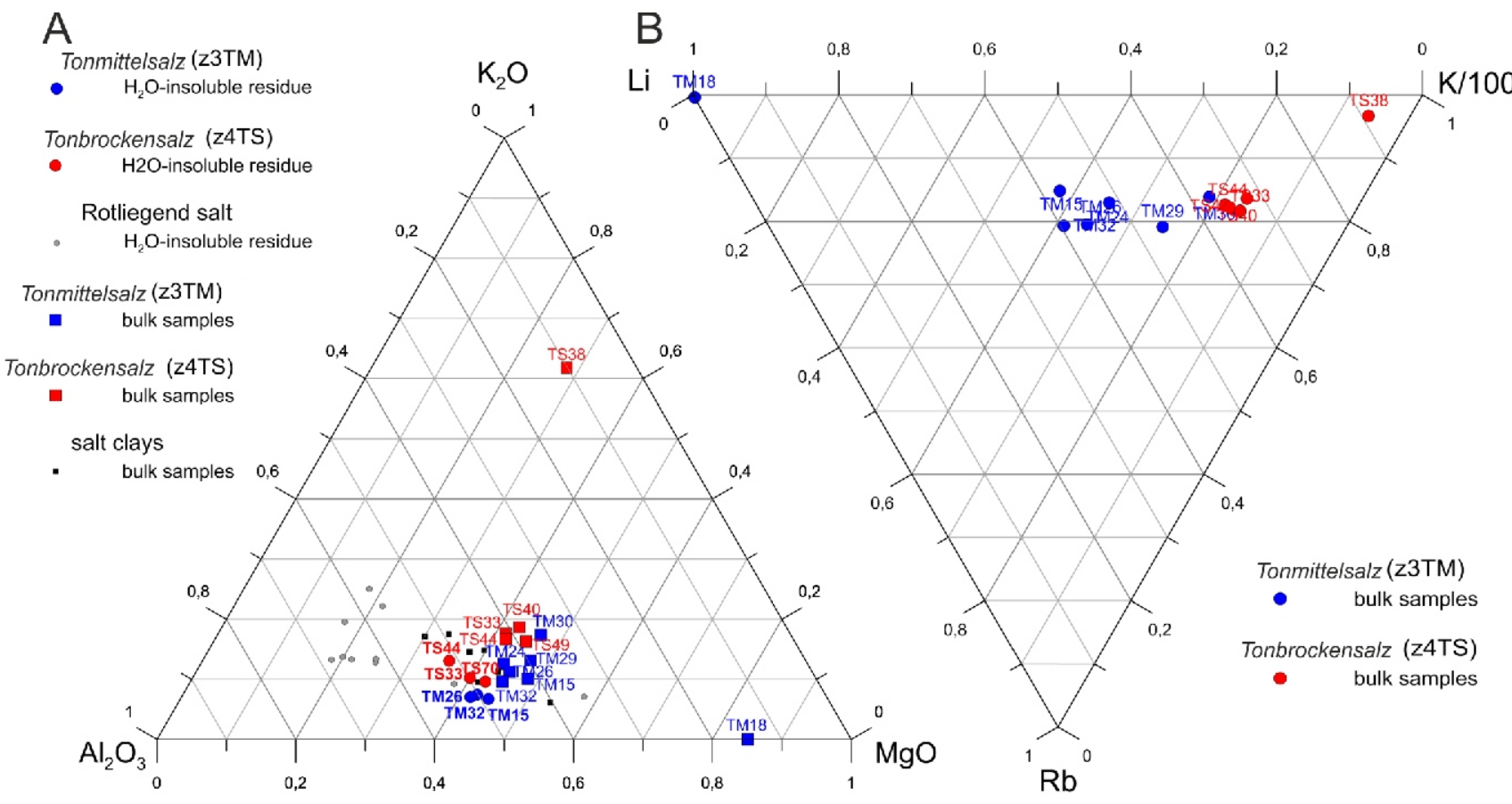

Fig. 19A - ternary diagram of $\mathrm{Al}_{2} \mathrm{O}_{3}-\mathrm{MgO}-\mathrm{K}_{2} \mathrm{O}$ (left hand side) of bulk samples (square) and $\mathrm{H}_{2} \mathrm{O}$-insoluble residue (circle, bold) of the Z3TM (blue), the Z4TS (red), salt-clay (black) and the Rotliegend salt (grey); B - ternary diagram of K-Li-Rb (right hand side) of bulk samples of the z3TM (blue) and the z4TS (red)

idue are minor components in both units and are slightly enhanced in the Z3TM with respect to the z4TS. Carnallite is an accessory mineral in both units and polyhalite is only common in the z4TS (except occasionally in sample TM18 of the anhydrite layer in z3TM1/na).

Halite matrix crystals in the z3TM show curved grain boundaries with often $120^{\circ}$ triple junctions. Within the halite fabric, rectangularly assembled internal fluid inclusion trails potentially look like chevrons, which form during sedimentation (Fig. 6D; e.g., Warren, 2016). Idiomorphic halite crystals within clay-bearing layers (Fig. 4 z3TM3/t, Fig. 5A-C) have probably been preserved in the clay-bearing matrix during diapirism. In the z4TS, the halite matrix show partly elongated crystal shapes, smoothly curved to straight grain boundaries with $120^{\circ}$ triple junctions, which may indicate dynamic recrystallization. Fluid inclusions are often observed on grain boundaries of halite crystals as well as within crystals (Fig. 13). Clay clasts also show an internal fabric of broken components, folded anhydrite layers and bedding (Fig. 14C, D). One can infer that this internal fabric evolved during sedimentation or diagenesis, while the brecciated fabric of clay and halite clasts in a recrystallized halite matrix developed during diapirism.
The rocks of the Z3TM exhibit clay-on-halite grain boundaries and include flakes and layers (Figs. 5 and 6). The distribution of the clay-bearing matrix and anhydrite is homogeneous, as shown by CT analysis (Fig. 9). In the z4TS, clay appears as vaguely aligned clasts in between halite grains (Figs. 14D and 16) and as coatings around halite crystals detected by CT (Fig. 16). The brecciated, deformed fabric of the z4TS indicate a deformation documented also by two fold limbs observed in the section investigated, which is located only $50 \mathrm{~m}$ away from the outer boundary of the salt diapir (Fig. 2).

Based on microscope observations and XRD, combined with the Rietveld-method, the clay-bearing matrix of both units shows a similar mineralogical composition with quantitative variations in parts (Table 3 ). This suggests a similar source of the detritus. Within the clay-bearing matrix, two clay minerals (chlorite-smectite and kaolinite) and the phyllosilicates chlorite and muscovite were observed. While muscovite and kaolinite originate from continental input, chlorite can be at least partly a product of the reaction of muscovite with Mg-enriched brine (Braitsch, 1971). The chlorite-smectite mixed layer mineral, which has a high amount of chlorite layers, reflects the transformation of smectite to chlorite (Bettison-Varga and Mackinnon, 1997). Quartz is mainly detrital (Figs. 5D, 13C and 15) and 
partly authigenic (Figs. 6D and 7B). Microcline is apparently very fine-grained and only detected by $\mathrm{XRD}$. The components of the $\mathrm{H}_{2} \mathrm{O}$-insoluble residue are similar for both units (except sample TM32), but the grain sizes differ. The grain size of matrix components in the Z3TM varies mainly between 50 and $150 \mu \mathrm{m}$ (Fig. 5), whereas in the z4TS, the grain size of components in the clay-bearing matrix is $<25 \mu \mathrm{m}$ with scattered larger anhydrite and quartz crystals (Figs. 13C and 14B). Differences in the grain size distribution could reflect different transport distances and mechanisms for continental detritus into the central part of the Zechstein basin, where Gorleben is located. Sample TM32 shows an enhanced content of quartz, kaolinite and chlorite in relation to all other samples, while no chloritesmectite occur and less muscovite. Either the origin of the detritus changed temporarily during z3TM3/t or the metamorphic reactions, like the completed transformation from smectite to chlorite, are different in this subunit.

Polyhalite occurs in both strata, but in the z3TM it was detected only in one distinct anhydrite layer of Z3TM1/na subunit (sample TM18; Fig. 8). In the z4TS, polyhalite associated with anhydrite crystals was often observed by polarizing microscopy (Fig. 14). Polyhalite originates from synsedimentary or diagenetic reactions of anhydrite with $\mathrm{Mg}-\mathrm{K}$-enriched brine (Braitsch, 1971).

Magnesite crystals in z3TM rocks with grain sizes up to $500 \mu \mathrm{m}$ show a high amount of impurities (Fig. 6C, D) Magnesite in the z4TS was detected by XRD with the Rietveld-method, not under the polarizing microscope, due to a crystal size $<5 \mu \mathrm{m}$. The formation of magnesite is associated with increased $\mathrm{Mg}$ content of an interacting brine (e.g., Schramm, 1995), while no primary magnesite, precipitated from seawater at $25^{\circ} \mathrm{C}$, has been found in general (e.g., Usdowski, 1994). During evaporation of seawater, the salinity and consequently the $\mathrm{Mg}$ concentration, increases in the brine. The sediment is not consolidated during this period, which leads to an Mg-enriched brine migrating into pore space, so that the primary calcite transforms during diagenesis to dolomite, followed by the transformation to magnesite, if the Mg-concentration increases with increasing salinity (e.g., Schramm, 1995). The petrographic investigations show that magnesite is tightly conjoined with idiomorphic quartz (Figs. 6D and 7B) suggesting that the magnesite has grown simultaneously with quartz.

Quartz with prismatic, idiomorphic shapes in halite crystals is present in both strata, but are more common in the Z3TM (Figs. 6D and 7B). Due to the idiomorphic habit of quartz, an authigenic formation is very likely. However, with $\sim 3 \mu \mathrm{g} / \mathrm{g}$ content of silica in seawater (Bruland, 1983), which corresponds to $6 \mu \mathrm{g} / \mathrm{g}$ content of amorphous $\mathrm{SiO}_{2}$, seawater contains very low concentrations of $\mathrm{SiO}_{2}$. At an evaporation level of halite precipitation (at $\sim 9$-fold seawater concentration), the $\mathrm{SiO}_{2}$ concentration of $\sim 60 \mu \mathrm{g} / \mathrm{g}$ in the sediment is still very low. Even at the carnallite precipitation level (at 95-fold seawater concentration), a concentration of $\sim 600 \mu \mathrm{g} / \mathrm{g} \mathrm{SiO}_{2}\left(0.06 \mathrm{wt}\right.$. $\left.\% \mathrm{SiO}_{2}\right)$ seems too low to account for the quantity of idiomorphic quartz detected in the samples of above $1 \mathrm{wt} . \%$. Therefore another source for $\mathrm{SiO}_{2}$ may be considered. For example, $\mathrm{SiO}_{2}$ can be generated during progressive evaporation and decreasing $\mathrm{pH}$, if phyllosilicates decompose and quartz is formed by crystallization from amorphous $\mathrm{SiO}_{2}$ (Braitsch, 1971)

Microscopically detected carnallite is present in both units studied. It indicates either a highly evolved evaporation level of seawater or a secondary formation. According to Mattenklott (1995), carnallite formation can be related to different processes, e.g. a process that promotes secondary carnallite formation is a metamorphic reaction between kieseritic carnallitite and solution R (e.g., Usdowski and Dietzel, 1998). The crystalli- zation of carnallite in the presence of clay minerals can also be related to filtration effects (Braitsch, 1971). Clay minerals absorb $\mathrm{H}_{2} \mathrm{O}$, leading to an increase of $\mathrm{Mg}$ and $\mathrm{K}$ concentration in the brine, enabling carnallite precipitation. Another possibility for metamorphic carnallite formation is the leaching of phyllosilicates by brine, which could provide the necessary $\mathrm{K}$ and/or Mg supply (Braitsch, 1971).

The proportions of characteristic major and minor components as in $\mathrm{Al}_{2} \mathrm{O}_{3}-\mathrm{MgO}-\mathrm{K}_{2} \mathrm{O}$ and $\mathrm{Rb}-\mathrm{K}-\mathrm{Li}$ ternary diagrams (Fig. 19) of the Zechstein units investigated and, for contrast, Zechstein salt-clays as well as Rotliegend salt (Lower Permian) show some differences. The z3TM and Z4TS display a higher $\mathrm{MgO}$ content whereas the Rotliegend salt samples e.g. show a higher $\mathrm{Al}_{2} \mathrm{O}_{3}$ content. The samples of the z3TM partly and slightly differ from samples of the $z 4 T S$ in $\mathrm{Al}_{2} \mathrm{O}_{3}, \mathrm{MgO}$ and $\mathrm{K}_{2} \mathrm{O}$ contents. The z4TS with partially higher concentrations of $\mathrm{K}_{2} \mathrm{O}$ (TS38, with a one magnitude less $\mathrm{Al}_{2} \mathrm{O}_{3}$ and $\mathrm{MgO}$, Table 5) and to some extent, the Z3TM is slightly enriched with respect to MgO. Two samples of the Z3TM and z4TS, TM18 and TS38, differ significantly in their geochemical composition in relation to ambient samples. Sample TM18 corresponds with the anhydrite layer in the z3TM1/na subunit (Fig. 8) and sample TS38 of the Z4TS was taken from a layer of very pure rock salt in the z4TSU subunit. The lack of detrital components cause the differences in geochemical composition between these two samples.

The relation $\mathrm{Rb}-\mathrm{K}-\mathrm{Li}$ also documents a distinct difference between the z3TM and the z4TS. The samples from the z3TM show higher Li concentrations, the Rb values vary little, while samples from the z4TS are enriched in K (Fig. 19). The higher amount of chlorite and muscovite in the z3TM is probably the reason for the higher $\mathrm{Li}$ concentration in comparison to the z4TS. Phyllosilicates may be a significant carrier of Li (Braitsch, 1971, Herrmann et al., 2003). Samples TM18 and TS38 are again exceptions due to depletion of Rb and $\mathrm{K}$ (sample TM18) or of Rb and Li (sample TS38), respectively. Plots of other element relations (Tables 2 and 5 ) did not show any significant difference between the two units.

The distribution of rare earth elements in bulk samples of the z3TM (Fig. 11) and z4TS (Fig. 20), normalized to chondrite, show similar trends. A negative Eu-anomaly can be observed in samples of both units. Differences were detected in the REE concentrations: in the Z3TM the REE are in part 10-fold higher than in the z4TS. The samples of the z3TM with higher REE concentrations match the REE values of the European Paleozoic Shale Composition (ES) well (Fig. 20; Haskin and Haskin, 1966; Herrmann and Wedepohl, 1967; Haskin et al., 1968). This indicates an origin of this material with geochemical signatures related to continental shale. The intermediate concentration in samples of the z3TM (around 10) correspond to higher concentrations in the samples of the z4TS and both show similarities with the REE concentrations of carbonates, published by Ronov et al. (1974) and Taylor and McLennan (1985). Samples of both units with lower concentrations of REE show a similar trend. The low concentrations may be related to a high halite content, which does not incorporate REE in significant quantities due to crystallization from seawater by evaporation. Only very low quantities can be incorporated in salt minerals within fluid inclusions. The REE concentrations of seawater (Elderfield and Greavens, 1982; Piepgras and Jacobsen, 1992), normalized to chondrite, are several magnitudes lower compared to data for evaporites according to Ronov et al. (1974) and Taylor and McLennan (1985) or the measured values of both Zechstein units studied. This shows that the main REE input originates from clay fraction components such as heavy minerals. Generally, the higher the clay fraction, the 


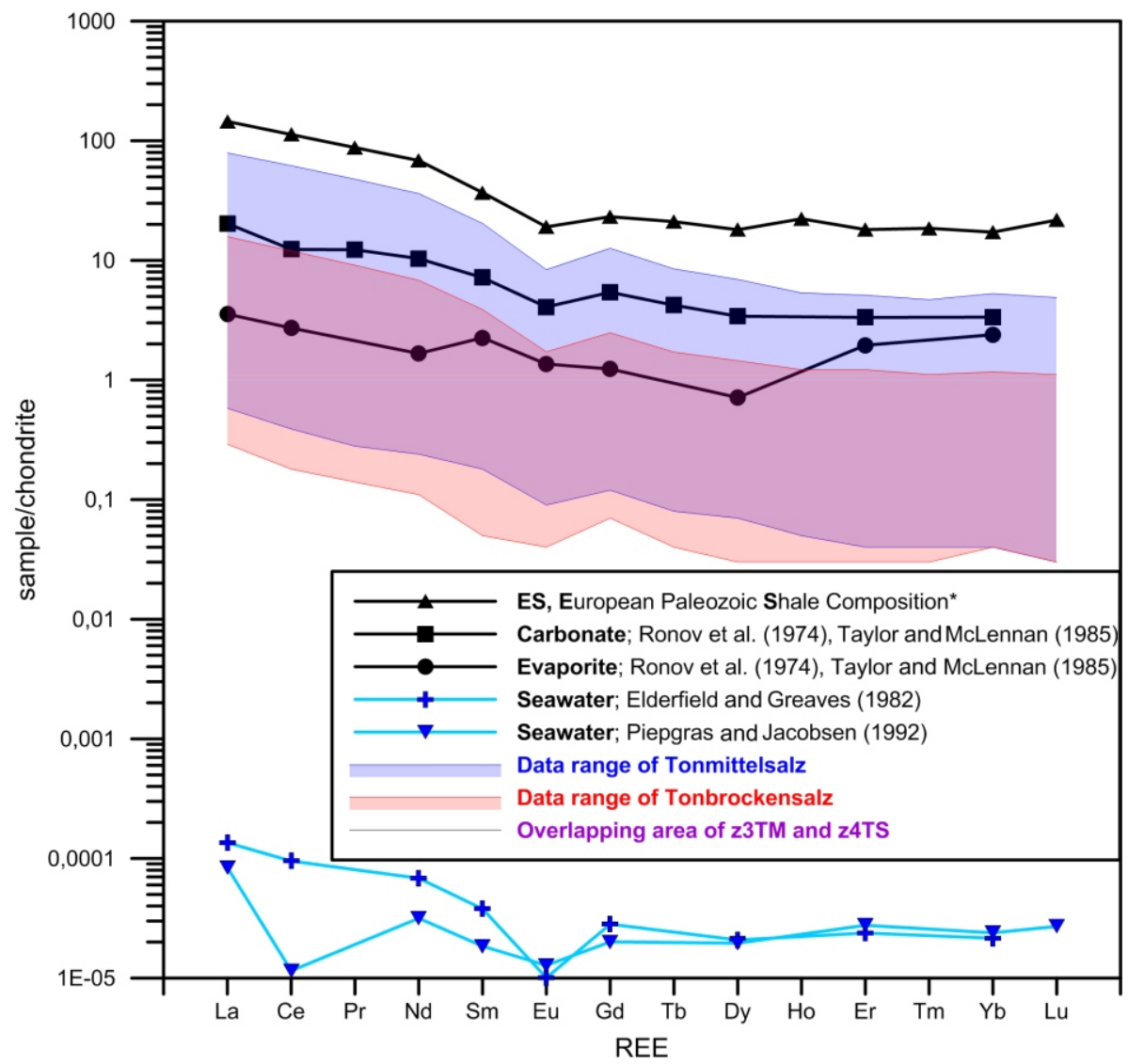

Fig. 20. REE distribution of different standards, normalized to chondrite (modified after Brammer, 1992) and data range of the z3TM (blue) and z4TS (red) with overlapping purple area

${ }^{*}$ Citation for ES in text

higher the REE concentrations. Even though sample TM32 displays the highest concentrations of REE, with $45 \mathrm{wt} \%$ the $\mathrm{H}_{2} \mathrm{O}$-insoluble residue is $12 \%$ lower than in sample TM26. Additionally, the phyllosilicate content of sample TM32 (49 wt.\% of $\mathrm{H}_{2} \mathrm{O}$-insoluble residue) is smaller than in sample TM26 with 66 wt. $\%$ of $\mathrm{H}_{2} \mathrm{O}$-insoluble residue. This means that within the less detritus-rich sample TM32, there is a higher content of heavy minerals compared to the other samples, which may be explained by a different source of the detritus.

Isotope data of both strata show values equivalent to those for the Zechstein (e.g., Peryt et al., 2010) and indicate no significant overprinting. The $\delta^{18} \mathrm{O}$ values of the z4TS rocks vary between 8.5 and $11.9 \%$, and may indicating changing conditions during formation like the influence of continental water ( $\mathrm{Ta}$ ble 5). In contrast, the range in the $\delta{ }^{34} S$ of the samples from the z4TS is very small (9.0 to $9.7 \%$ ). The $\delta^{18} \mathrm{O}$ and $\delta^{34} \mathrm{~S}$ isotope values of the Z3TM deposits show only a small range between 9.4 and $10.4 \%$, indicating no relevant changes in the conditions during sedimentation and diagenesis (Table 2).

Based on the descriptions of the Brown Zuber (Wachowiak et al., 2014) and the Red Zuber (Natkaniec-Nowak et al., 2014) of the Polish Zechstein succession, both units studied in the NGZB show some similarities to the equivalent zuber beds in the PZB (Fig. 1). The Z3TM and the Brown Zuber rocks are characterized by a very similar mineral composition and fabric, such as idiomorphic halite crystals up to several $\mathrm{cm}$ in size in a clay-bearing matrix, or idiomorphic quartz and carbonate (magnesite and rarely dolomite) crystals. A similar mineralogical composition was also observed for the z4TS and the Red
Zuber rocks. A disordered, brecciated fabric of halite blasts and clasts of clay substances in a fine-grained halitic matrix were documented in both of these units.

\section{CONCLUSIONS}

The Tonmittelsalz (z3TM) and Tonbrockensalz (z4TS) lithostratigraphic units of the German Zechstein succession are characterized by a similar mineral composition of mainly halite as well as minor amounts of anhydrite and a clay-bearing matrix. However, differences were observed through detailed investigations of the rocks. The older Z3TM rocks document some primary features like chevrons in halite crystals and idiomorphic halite crystals in clay-bearing layers. A brecciated fabric with recrystallized halite matrix and a vague layering, shown by polarizing microscopy and CT-imaging, indicate a deformation of the younger z4TS during diapirism, which is folded in the deep borehole Go1004 and is located only 50 m away from the outer boundary of the salt diapir. Internal fabrics of clay clasts show an early brecciated and folded fabric during sedimentation or diagenesis of the z4TS. Displayed by CT, the distribution of the clay-bearing matrix and anhydrite in the z3TM are homogeneous. The $\mathrm{H}_{2} \mathrm{O}$-insoluble residue consists of quartz, clay minerals (chlorite-smectite and kaolinite), chlorite and muscovite as well as accessory microcline, magnesite and hematite. These components show similar quantities within the clay-bearing matrix of both units except in the z3TM3/t, but the amount of clay-bearing matrix is enhanced in the z3TM rocks 
and the components display smaller grain sizes in the rocks of the z4TS. The lack of chlorite-smectite in the z3TM3/t is unique in all subunits of z3TM and z4TS and reflects a temporary change of the detrital origin or varied metamorphic reactions supported by REE observations. Polyhalite associated with anhydrite is predominant in the z4TS. In the z3TM, magnesite crystals are visible under the polarizing microscope and SEM, while in the z4TS the magnesite is too small to detect Magnesite crystals are often conjoined with idiomorphic quartz crystals, which probably have formed simultaneously. These authigenic quartz crystals needed a higher amount of $\mathrm{SiO}_{2}$ for formation than may be sourced from evaporating seawater. Therefore, leached phyllosilicates are a likely $\mathrm{SiO}_{2}$-source. Major and minor components of the Z3TM and Z4TS both plot on a ternary $\mathrm{Al}_{2} \mathrm{O}_{3}-\mathrm{MgO}-\mathrm{K}_{2} \mathrm{O}$ diagram in a typical area with salt clays, but away from continent-influenced Rotliegend salt. The z3TM rocks contain higher values of trace elements like $\mathrm{Li}$ and higher values in REE, while the z4TS rocks are enriched in K. Isotope data of anhydrites of both units correspond to those of the Zechstein. The $\delta^{18} \mathrm{O}$ values of samples from the z4TS display a relatively large range $(8.5-11.9 \%$ ) and may indicate changing conditions during its formation. In contrast, only minor variations in the $\delta^{34} S$ of samples from the z4TS and in both isotope compositions of samples from the Z3TM have been documented. The z3TM and z4TS deposits from the North German Basin show some similarities to the equivalent zuber beds of the Polish Zechstein Basin.

Acknowledgements. The authors like to thank T.M. Peryt Granoszewski, W.G. Czapowski, T. Toboła and J. Garcia-Veigas for their critical reviews and constructive comments, which greatly improved this paper. Furthermore, special thanks to the team of Prof. H. Strauss from the Institute of Geology and Palaeontology at the University of Münster for performing the isotope analyses, to Dr. J. Walter from MAS-Analytics in Göttingen for the analyses of bulk samples, Dr. N. Thiemeyer from the X-RAY Lab in Wolfsburg for CT analysis, the staff of the geochemical lab in Geozentrum Hannover, R. Götze and $T$. Faust for sample preparation and R. Dohrmann and K. Ufer for XRD measurements (all four at BGR).

\section{REFERENCES}

Bettison-Varga, L., Mackinnon, I.D.R., 1997. The role of randomly mixed-layered chlorite/smectite in the transformation of smectite to chlorite. Clays and Clay Minerals, 45: 506-516.

Bornemann, O., 1991. Zur Geologie des Salzstocks Gorleben nach den Bohrergebnissen. BfS-Schriften, Salzgitter.

Bornemann, O., Fischbeck, R., 1988. Salzstockuntersuchung Gorleben 1004. Schichtenverzeichnis ab Oberfläche des Salzstocks (Stand. April 1988). Ergebnisbericht. Bundesanstalt für Geowissenschaften und Rohstoffe, Hannover.

Bornemann, O., Behlau, J., Fischbeck, R., Hammer, J., Jaritz, W., Keller, S., Mingerzahn, G., Schramm, M., 2008. Description of the Gorleben Site. Part 3: Results of the geological surface and underground exploration of the salt formation. Bundesanstalt für Geowissenschaften und Rohstoffe Hannover.

https://www.bgr.bund.de/EN/Themen/Endlagerung/Produkte/pr odukte node en.html

Boyton, W.V., 1984. Cosmochemistry of the rare earth elements: Meteorite studies. In: Rare Earth Geochemistry (ed. P. Henderson). Elsevier, Amsterdam-Oxford-New York-Tokyo.

Brammer, K.-J., 1992. Stoffbestand und Lanthanidenverteilung der wasserlöslichen Mineralfraktion in marinen Zechsteinevaporiten. Dissertation. Cuvillier Verlag, Göttingen.

Braitsch, O., 1971. Salt Deposits, Their Origin and Composition. Springer Berlin, Heidelberg, New York.

Bruland, K.W., 1983. Trace elements in sea water. Chemical Oceanography, 8: 157-220.

Czapowski, G., Tomassi-Morawiec, H., 2013. Palaeogeographic and palaeoclimate factors of salinity fluctuations in the eastern part of the Late Permian (Zechstein) European Basin: case study from the salt basin in Poland. Geological Society Special Publications, 376.

Elderfield, H., Greavens, M.J., 1982. The rare earth elements in seawater. Nature, 296: 214-219.

Haskin, M.A., Haskin, L.A., 1966. Rare earths in European shales: a redetermination. Science, 154: 507-509.

Haskin, L.A., Frey, F.A., Wildeman, T.R., 1968. Relative and absolute terrestrial abundances of the rare-earths. In: Origin and Distribution of the Elements (ed. L.A. Ahrens): 889-912. Pergamon, New York.
Herde, W., 1953. Die Riedel Gruppe im Zentralen Teil des Nordwestdeutschen Zechsteingebietes (Stratigraphie, Genese und Paläontologie). Ph.D. thesis. Göttingen.

Herrmann, A.G., Wedepohl, K.H., 1967. Die quantitative Bestimmung der Seltenen Erden (La-Lu) und Yttriums in silicatischen Gesteinen. Zeitschrift für analytische Chemie, 225: 255-274.

Herrmann, A.G., Siewers, U., Harazim, B., Usdowski, E., 2003. Kriterien zur Beurteilung von Salzlösungen in den Zechsteinevaporiten Mittel- und Norddeutschlands. Kali und Steinsalz 3: 24-35.

Käding, K.-C. 2000. Die Aller-, Ohre-, Friesland- und Fulda-Folge (vormals Bröckelschiefer-Folge). Kali und Steinsalz 13: 86-96.

Klarr, K., Paul, J., 1991. Der Übergang vom Zechstein zum Buntsandstein in den Bohrungen Remlingen 5 und Remlingen 9 (Asse bei Braunschweig). Zentralblatt für Geologie und Paläontologie, Teil I: 913-928.

Mattenklott, M., 1995.Modellberechnungen zur $\mathrm{Br}$ - und $\mathrm{Rb}-\mathrm{Ver}-$ teilung in Carnallitgesteinen. Kali und Steinsalz, 11: 341-344.

Mertineit, M., Schramm, M., Hammer, J., Zulauf, G., 2014. Deformation of anhydrite rocks (Gorleben-Bank, z3OSM) in a high-strain domain of the Gorleben salt dome, Germany. Zeitschrift der Deutschen Gesellschaft für Geowissenschaften, 165: 49-62.

Montinaro, A., Strauss, H., Mason, P.R.D., Roerdink, D., Münker, C., Schwarz-Schampera, U., Arndt, N.T., Farquhar, J., Beukes, N.J., Gutzmer, J., Peters, M., 2015. Paleoarchean sulfur cycling: multiple sulfur isotope constraints from the Barberton Greenstone Belt, South Africa. Precambrian Research, 267: 311-322.

Natkaniec-Nowak, L., Wachowiak, J., Stach, P., 2014. Mineralogical and petrological characteristics of Red Zuber (Na4t) deposits from the borehole M-34 of the Mogilno Salt Dome. Przegląd Solny, 10: 13-24.

Peryt, T.M, Hałas, S., Hryniv, S.P., 2010. Sulphur and oxygen isotope signatures of late Permian Zechstein anhydrites, West Poland: seawater evolution and diagenetic constraints. Geological Quarterly, 54 (4): 387-400.

Piepgras, D.J., Jacobsen, S.B., 1992. The behavior of rare earth elements in seawater: precise determination of variations in the North Pacific water column. Geochimica et Cosmochimica Acta, 56: 1851-1862. 
Rietveld, H., 1969. A profile refinement method for nuclear and magnetic structures. Journal of Applied Crystallography, 2: 65-71.

Ronov, A.B., Balashov, Y.A., Girin, Y.P., Bratishko, R.K. Kazakova, G.A., 1974. Regularities of rare-earth element distribution in the sedimentary shell and in the crust of the earth. Sedimentology, 21: 171-193.

Schramm, M., 1995. Die Minealparagenesen des magnesitführenden norddeutschen Zechsteins. Eine mineralogische, petrologische und geochemische Untersuchung. Dissertation. Cuvillier, Göttingen.

Seal, R.R.I., Alpers, C.N., Rye, R.O., 2000. Stable isotope systematics of sulfate minerals. Reviews in Mineralogy \& Geochemistry, 40: 541-593.

Słowakiewicz, M., Mikołajewski, Z., 2011. Upper Permian Main Dolomite microbial carbonates as potential source rocks for hydrocarbons (W Poland). Marine and Petroleum Geology, 28: 1572-1591.

Taylor, S.R., McLennan, S.M., 1985. The Continental Crust: Its Composition and Evolution. Blackwell Scientific Publications, Oxford-London-Edinburgh-Boston-Palo Alto-Melbourne.

Thiemeyer, N., Habersetzer, J., Peinl, M., Zulauf, G., Hammer, J., 2015. The application of high resolution X-ray computed tomography on naturally deformed rock salt: Multi-scale investigations of the structural inventory. Journal of Structural Geology, 77: 92-106.

Usdowski, E., 1994. Synthesis of dolomite and geochemical implications. International Association of Sedimentologists Special Publication 21: 345-360.

Usdowski, E., Dietzel, M., 1998. Atlas and Data of Solid-Solution Equilibria of Marine Evaporites. Springer Berlin, Heidelberg, New York.

Wachowiak, J., Natkaniec-Nowak, L., Smolinski, W., 2014. Mineralogical and petrographic characteristics of Brown Zuber (Na3t) deposits from the borehole M-34 of the Mogilno Salt Dome (in Polish with English summary). Przegląd Solny, 10: 25-38.

Wagner, R., 1991. Stratigraphie des höchsten Zechsteins im Polnischen Zentralbeckens. Zentralblatt für Geologie und Paläontologie, Teil I, 4: 883-892.

Wagner, R., 1994. Stratigraphy and evolution of the Zechstein basin in the Polish Lowland. Prace Państwowego Instytutu Geologicznego, 146: 1-71.

Wagner, R., Peryt, T.M., 1997. Possibility of sequence stratigraphy subdivision of the Zechstein in the Polish Basin. Geological Quarterly, 41 (4): 457-474.

Warren, J.K., 2016. Evaporites: Sediments, Resources and Hydrocarbons. Springer Berlin, Heidelberg, New York. 